\title{
Elucidating multipollutant exposure across a complex metropolitan area by systematic deployment of a mobile laboratory
}

\author{
I. Levy ${ }^{1,{ }^{*}}$, C. Mihele ${ }^{1}$, G. Lu ${ }^{1}$, J. Narayan ${ }^{1}$, N. Hilker ${ }^{1}$, and J. R. Brook ${ }^{1}$ \\ ${ }^{1}$ Air Quality Research Division, Science and Technology Branch, Environment Canada, Downsview, Ontario, Canada \\ *now at: Technion Center of Excellence in Exposure Science and Environmental Health, Technion I.I.T., Israel
}

Correspondence to: J. R. Brook (jeff.brook@ec.gc.ca)

Received: 4 September 2012 - Published in Atmos. Chem. Phys. Discuss.: 7 December 2012

Revised: 20 April 2014 - Accepted: 19 May 2014 - Published: 16 July 2014

\begin{abstract}
This study evaluates a deployment strategy of a heavily instrumented mobile lab for characterizing multipollutant spatial patterns based upon a limited number of measurement days spread over different seasons. The measurements obtained through this deployment strategy are used to gain insight into average pollutant levels between routine monitoring sites and in relation to emission sources in the region, as well as to assess correlations between pollutant patterns to better understand the nature of urban air pollutant mixtures. A wide range of locations were part of the deployment in order to characterize the distribution of chronic exposures potentially allowing development of exposure models. Comparison of the mobile lab averages to the available adjacent air quality monitoring network stations to evaluate their representativeness showed that they were in reasonable agreement with the annual averages at the monitoring sites, thus providing some evidence that, through the deployment approach, the mobile lab is able to capture the main features of the average spatial patterns. The differences between mobile lab and network averages varied by pollutant with the best agreement for $\mathrm{NO}_{2}$ with a percentage difference of $20 \%$. Sharp differences in the average spatial distribution were found to exist between different pollutants on multiple scales, particularly on the sub-urban scale, i.e., the neighborhood to street scales. For example, $\mathrm{NO}_{2}$ was observed to be $210-265 \%$ higher by the main highway in the study region compared to the nearby urban background monitoring site, while black carbon was higher by $180-200 \%$ and particle number concentration was $300 \%$ higher. The repeated measurements of near-roadway gradients showed that the rate of change differed by pollutant with elevated concentrations detected up to $600-700 \mathrm{~m}$ away for some pollutants. These re-
\end{abstract}

sults demonstrate that through systematic deployment mobile laboratory measurements can be used to characterize average or typical concentration patterns, thus providing data to assess monitoring site representativeness, spatial relationships between pollutants, and chronic multipollutant exposure patterns useful for evaluating and developing exposure models for outdoor concentrations in an urban environment.

\section{Introduction}

Long-term or chronic exposure to air pollution has been shown in many epidemiological studies of different types, such as cohort studies, case-control studies and cross sectional studies, to be associated with adverse human health outcomes (Ren and Tong, 2008). While most studies have focused on correlations of outcomes (e.g., mortality) with a small number or even a single pollutant (e.g., $\mathrm{PM}_{2.5}, \mathrm{NO}_{2}$ ) (Adar et al., 2013; Jerrett et al., 2009; Pope and Dockery, 2006), it is generally believed that no single pollutant is solely responsible; rather, features of the mix of pollutants in the air, particularly when the myriad of possible adverse health effects is considered, are more likely to be exerting the effects, possibly synergistically (Mauderly and Samet, 2009). Furthermore different pollutants in the mix likely have different effects exhibited by different endpoints, acting through different mechanisms.

In studies where exposure to a single pollutant is used for assessing associations with health outcomes, it is often acknowledged that this pollutant is a proxy for a specific source or more complex mixture of concern. For example, $\mathrm{NO}_{2}$, ultrafine particles (particles with a dynamic range of 
$>0-100 \mathrm{~nm}$ ) and black carbon (BC) are often considered as proxy pollutants for traffic-related air pollution (TRAP) or fossil fuel combustion in general (e.g., Brook et al., 2007; Bukowiecki et al., 2003; Crouse et al., 2010; Janssen et al., 2011). $\mathrm{SO}_{2}$ is thought of as a proxy for coal-fired power plants and certain heavy industries such as emissions from petroleum refineries (e.g., Smargiassi et al., 2009) and benzene could be related to both of these sources in some cities (Wheeler et al., 2008) or mainly to one in others (Levy et al., 2014). $\mathrm{PM}_{2.5}$ is perhaps the pollutant of greatest interest (Brook et al., 2010) and is itself a mixture of compounds related to multiple sources and/or secondary formation processes. While it is generally suspected that certain types of $\mathrm{PM}_{2.5}$, related to certain sources or chemical composition, are more likely responsible for health effects and that this could vary by outcome, this has yet to be demonstrated with enough confidence to explicitly support more-focused policies (Kelly and Fussell, 2012; Lippmann et al., 2013; Rohr and Wyzga, 2012).

The air pollutant mix we breathe as urban dwellers is the result of multiple emission sources (traffic, industry, residential, commercial and biogenic activities), each of which emits a different distribution of constituents. Many of these directly emitted primary pollutants are subsequently involved in reactions in the atmosphere to produce secondary pollutants (e.g., $\mathrm{NO}+\mathrm{O}_{3}$ to form $\mathrm{NO}_{2}$; nitrogen oxides $\left(\mathrm{NO}_{\mathrm{x}}\right)$ and volatile organic compounds (VOC) interacting to form ozone in the presence of sunlight; secondary organic aerosols derived from oxidation of VOCs). Given the spatial variability in pollution sources and sinks over short distances, the heterogeneity in the pollutant mix emitted and the nonlinearity and varying timescales of secondary formation processes, the urban environment is challenging with respect to accurate characterization of air pollutant patterns and subsequent estimates of population and individual-level long-term or chronic exposures (e.g., Costabile et al., 2009; Freiman et al., 2006). It should be noted that other factors also take part in determining exposure such as indoor-outdoor infiltration and individual time activity patterns (Monn, 2001). These factors can obscure how well outdoor spatial contrasts represent actual exposure leading to apparent modification of the effect of ambient concentrations (e.g., Janssen et al., 2002).

Although different methods for estimating chronic human exposure patterns across urban areas are being used, ultimately they all depend upon measurements of concentrations at multiple locations that ideally reflect long-term average conditions and the range of levels that occur across space. Such measurements are used to develop empirical models and/or to validate physically based models predicting concentrations based upon meteorological and emissions data. Point measurements obtained at routine air quality (AQ) monitoring sites have been used for both of these purposes (e.g., Beckerman et al., 2013; Cyrys et al., 2005; Hystad et al., 2011; Yuval et al., 2013) and they have the advantage of capturing long-term conditions. However, because routine monitoring tends to focus on urban background locations, particularly in North America, the data are rarely able to sufficiently capture the spatial variability existing in the urban environment (Wheeler et al., 2008), failing to adequately quantify the peak concentrations and hence the actual concentration and chronic exposure gradients. Clearly, spatial interpolation of the same AQ site data (e.g., ordinary kriging and inverse distance weighting) will also fail to show the true spatial pattern in concentration since this approach does not take into consideration urban features like road networks, point sources and green spaces that influence local emissions and concentrations (Jerrett et al., 2007).

Intensive campaigns that deploy on the order of 10-100 monitors across a city over limited time periods have successfully been used in many cities to obtain information that more realistically captures the concentration gradients. These "saturation monitoring" data sets can then serve as the source of the dependent variable in empirical exposure model development, such as land use regression (LUR) (e.g., Brauer et al., 2003; Henderson et al., 2007; Johnson et al., 2010; Kanaroglou et al., 2005). These approaches may also include data sets collected sequentially to increase the overall number of locations with active sampling for measurement of particles, although this requires temporal adjustments (e.g., Cyrys et al., 2005; Eeftens et al., 2012; Hochadel et al., 2006; Wang et al., 2013) or more complex spatial-temporal modeling methodologies (Gryparis et al., 2007; Szpiro et al., 2010) in the model development. Since the magnitude of the temporal adjustment can also vary spatially and is not well characterized, this can result in additional uncertainty in estimates of the long-term spatial patterns.

Dispersion models that predict the spatial pattern across the entire urban area (Cyrys et al., 2005; Hirtl and BaumannStanzer, 2007) or within the grid squares of more-advanced numerical models (Beevers et al., 2012; Isakov et al., 2007a; Nordling et al., 2008) have also been developed for estimating chronic human exposure patterns. These more physically based dispersion modeling approaches are limited by the accuracy and level of detail of the meteorological and emissions input data and are generally used for predicting the spatial pattern of a small number of tracer pollutants (i.e., nonreactive). More-advanced models, such as CMAQ, have also been considered directly for chronic exposure assignment (Marshall et al., 2008) and have the potential advantage of predicting concentrations of multiple primary and secondary pollutants in a consistent and comprehensive manner, although with varying degrees of confidence. However, they are limited by the grid cell size of a few square kilometers at best, and therefore cannot resolve sub-grid (i.e., neighborhood scale) variability. Hybrid approaches combining physical and empirical models in order to represent exposure across grid and sub-grid scales have also recently been proposed (Crooks and Isakov, 2013; Yuval et al., 2013). 
Despite the need for intensive monitoring campaigns, spatial or spatial-temporal empirical models are thus far the most common approach for chronic exposure prediction within urban areas. As a result, they have been applied successfully in a large number of epidemiological studies in North America and Europe (e.g., Brauer et al., 2007, 2008; Brook et al., 2008; Crouse et al., 2010; Gehring et al., 2010; Jerrett et al., 2009; Rivera et al., 2013; Thiering et al., 2013; Villeneuve et al., 2013). One limitation with these approaches is the small number of air pollutants they consider because of difficulty in simultaneously measuring multiple pollutants during the multisite intensive campaigns. As a result, it remains difficult to fully explore multipollutant exposures to study their combined effect or to assess the differential effects of different pollutants or to gain insight regarding the characteristics of the pollutant mixtures typically being represented by single indicator pollutants (Levy et al., 2014).

Mobile laboratories have also frequently been used for examining intra-urban variability of a range of air pollutants and may provide an alternate approach for obtaining data for spatial or spatial-temporal empirical model development (e.g., Larson et al., 2009; Patton et al., 2014). If sufficiently large to house and power multiple instruments, and if deployed in a systematic manner, mobile labs could potentially generate comparable data to the traditional fixed-site intensive monitoring campaigns for multiple air pollutants simultaneously.

Mobile labs or mobile measurement strategies have often been used to obtain highly resolved measurements both in time and space, but typically during relatively short time periods and for a limited number of pollutants (Bukowiecki et al., 2003; Durant et al., 2010; Fujita et al., 2011; Hagler et al., 2010; Isakov et al., 2007b; Weimer et al., 2009; Westerdahl et al., 2005; Zwack et al., 2011). Short-term measurement campaigns are common in atmospheric chemistry and air quality studies (e.g., Daum et al., 2003; Brook et al., 2013; Pennington et al., 2012), and for exploring chemical and physical processes, the short time frame may not be a limitation if relevant cases are captured. However, for describing spatial and temporal behavior, such as intra-urban variability for informing and developing empirical population exposure models (e.g., Dijkema et al., 2011) or the nature and frequency of certain events of interest (e.g., exceedance of guidelines), it is important to consider the representativeness of the short-term study period. Yet this is rarely examined rigorously, though it can be relevant for framing the conclusions in the proper context.

Similarly, while saturation monitoring has proven to be useful for exposure model development, it is also important consider whether the time period(s) when the intensive campaign is conducted characterizes actual long-term spatial gradients. Capturing a typical period is challenging because of temporal variability in meteorology. Jerrett et al. (2007) compared their intensive campaign measurements and the $\mathrm{NO}_{2}$ predictions from the model they developed to longer-term values reported at monitoring sites. Differences of up to $26 \%$ were observed, although this could only be assessed for a few sites. Xu et al. (2007) examined representativeness versus number of measurements for multiple pollutants and several Canadian cities. For VOCs Miller et al. (2012) showed that measurements in the transition seasons tend to be more representative. Consistent with this, Henderson et al. (2007) carried out their two-week Vancouver, British Columbia, monitoring campaigns in the late winter and late summer based upon the greatest likelihood of representativeness. In terms of chronic exposure rankings, Wheeler et al. (2008) compared the variation observed across 54 sites in Windsor, Ontario, among seasons. They found Spearman correlations between an individual season and the average pattern among seasons of 0.84 (summer) to 0.97 (spring) for $\mathrm{NO}_{2}$. This range decreased to $0.75-0.93$ for $\mathrm{SO}_{2}$, but overall the ranking of locations captured by a discrete two-week period appeared to be stable. Wheeler et al. (2008) obtained similar results for benzene and toluene. Cyrys et al. (2006) compared the annual, seasonal and monthly means calculated from daily $\mathrm{PM}_{2.5}$ measurements taken over seven days per month for one year to daily measurements taken on all days of the same year in Erfurt, Germany. They found that while the annual and seasonal means showed small bias $\left(1.7 \mu \mathrm{g} \mathrm{m} \mathrm{m}^{3}\right.$ and $2.7 \mu \mathrm{g} \mathrm{m}^{3}$, respectively), the monthly means "can only be considered to be a crude estimate that may substantially under- or overestimate the true monthly mean value".

Mobile measurements have two main challenges associated with their use for examining long-term average air pollutant patterns. The first is the fact that a mobile lab can only measure one location at a time and the second is that a relatively limited number of measurement days can be done because of the costs involved, particularly when large, heavily instrumented mobile labs are involved. A systematic approach is therefore needed to efficiently characterize representative long-term patterns of the multipollutant mix in a complex urban environment from mobile measurements. This approach should involve multiple measurements at the same locations over different days and different seasons with high spatiotemporal resolution and with a large suite of measuring devices examining both gaseous and particulate pollutants simultaneously.

In this study, high-resolution mobile measurements of multiple air pollutants were taken in the city of Montreal, Quebec, Canada, over multiple days with a focus on multipollutant spatial contrasts. The underlying hypothesis explored is that a systematic deployment strategy of a mobile laboratory can produce measurements that are representative for long-term exposure levels and gradients within urban areas. Therefore, the objectives of this paper are to evaluate a deployment strategy of a mobile lab in a large city undertaken to characterize longer-term average concentrations relevant to chronic exposures and then to apply the location-average data collected by this strategy to assess multiscale, multipollutant spatial contrasts in order to reveal more about sources 
and hotspots and how exposure potentially varies within the population. This is hoped to move us closer to understanding urban mixtures and to provide insight to help in the interpretation and development of epidemiological studies and statistical methods that seek to address the multipollutant exposure and health effect questions, particularly as it pertains to TRAP.

\section{Methods}

Air quality and meteorological measurements were taken by Environment Canada's mobile lab: Canadian Regional and Urban Investigation System for Environmental Research (CRUISER). CRUISER is a diesel engine vehicle (GMC C7500 medium-duty truck) equipped with a power generator and climate control systems that maintain stable conditions inside the customized vehicle body, housing researchgrade measurement instruments. To maximize data collection during deployments, CRUISER measurements are typically taken on a $24 \mathrm{~h}$ basis for the entire period of time it is present in a study location. Thus, much of the data are obtained when the vehicle is parked and plugged in at its "home base" location. Depending upon the study objectives, there are typically multiple periods of mobile measurements when CRUISER drives and measures, occasionally stopping to obtain fixed point data, meteorological measurements and to cross-reference with existing AQ monitoring sites.

\subsection{Study area}

The study was conducted on the Island of Montreal, which has 1.8 million inhabitants (Statistics Canada, 2011), and the population in the city of Montreal and the surrounding area is 3.8 million, making it the second largest city in Canada (Statistics Canada, 2011). As with most large cities, air pollution in Montreal is spatially variable (Crouse et al., 2009; Gilbert et al., 2005). Pollution sources on the island besides traffic include a variety of industrial activities, oil and gas refining, storage and distribution facilities, petrochemicals, metal refining, light manufacturing, multiple port areas and heating (in the winter) (Environment Canada, 2006). Figure 1 shows a map of the city, providing information on the different land uses, main roads and major point sources.

\subsection{Measurements}

The Montreal measurement campaign was conducted during 2009 in three seasons (winter, summer and autumn), with the combined analysis of the entire period referred to as the campaign average. There was an approximately three-week deployment in each season (13 January-11 February, 08 July03 September, 19 November-03 December), and this paper focuses on the mobile portion of these measurements (i.e., excluding times CRUISER was parked overnight and other non-driving days) in order to characterize spatial patterns in detail.

Measurements of 19 different parameters were taken simultaneously from the CRUISER platform throughout the campaign at time resolutions ranging from $0.5 \mathrm{~s}$ to $2 \mathrm{~min}$. Four additional species were derived from the measurements. Geolocation was recorded with a Garmin 176C GPS system every second and CRUISER's speed was determined from the GPS data. A list of the parameters measured, instruments used, their temporal resolution and the detection limit is given in Table 1. The inlets for the air quality instruments were located at the roof of the vehicle, $3.6 \mathrm{~m}$ a.g.l. oriented near the front left side. The GRIMM dust monitor, used for particle mass measurements (i.e., $\mathrm{PM}_{10}, \mathrm{PM}_{2.5}$ and $\mathrm{PM}_{1.0}$ ), had a separate inlet to enable the capture of coarse particles, but due it is slow flow rate and the impact of horizontal speed on the capture efficiency of larger particles, a correction based upon CRUISER's speed was applied. A description of the inlets and data management is given in Supplement C. Speed correction to the GRIMM particle measurements is discussed in Supplement D.

Data were flagged for invalid periods, below detection limit and missing values for each instrument. The data were then combined to create one data set with the time increment set to $1 \mathrm{~s}$, and instruments with greater time intervals were given repeating values to reflect the more integrated sampling. Although the spatial allocation of the measurements with longer time intervals is not as refined as for those with the $1 \mathrm{~s}$ time resolution, the road segments are sampled differently each time the route is driven and therefore the multiple repetitions of the route have good potential to spatially resolve the concentration patterns to finer scales than the distance traveled at these times would imply. An additional flag was used to indicate the likely impact of CRUISER's own plume when it was at stop sites (Fig. 1), so as to exclude such measurements in the analysis. Data from multiple studies indicate that this impact was most likely occurring when the vehicle speed was $<10 \mathrm{~km} \mathrm{~h}^{-1}$; brief peak concentrations are observed with NO levels $\geq 20$ ppbv and particle counts $>3000 \# \mathrm{cc}^{-1}$. This resulted in $4 \%$ of the mobile measurements being flagged; from this, those occurring at stop sites were excluded.

\subsection{Mobile measurement strategy for estimating longer-term averages}

The strategy for CRUISER's mobile measurements was to travel along predefined routes, passing along or near highways, main roads and local streets, as well as residential, commercial and industrial areas (Fig. 1c). Two routes were determined and systematically followed: (1) east Montreal and (2) central and west Montreal. The east route was used most often due to greater impact of industrial emissions and because of an asthma study being conducted in that part of the city (Dobbin et al., 2011). For both routes, the starting 


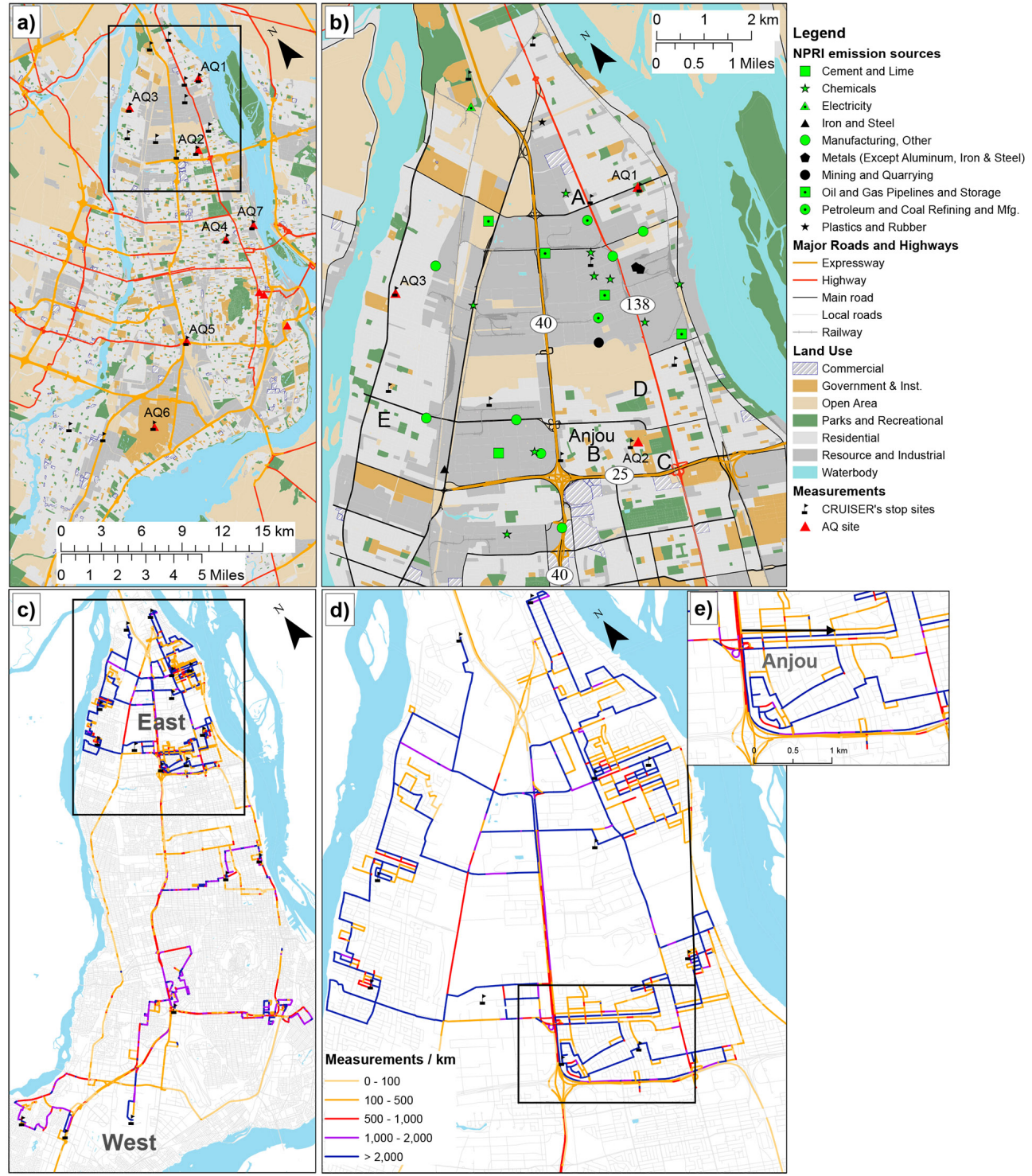

Figure 1. Map of the study area showing major roads, land use types, major emission sources and CRUISER's stop sites (a), with a higher resolution on the east part (b), as well as measurement density per kilometer of road segment (measurements / $\mathrm{km}$ ) for the annual period (c) and at higher resolution on the east part (d) and the Anjou neighborhood (e). Letters A-E in (b) refer to areas discussed in Sect. 3.3 and Fig. 4. The black arrow in (e) refers to the cross section discussed in Sect. 3.4 and Figs. 6 and 7.

point of travel along the route was changed randomly each day so as to avoid sampling the same location at the same time of day. On any given mobile measurement day, which was typically between 09:00-20:00 EST (i.e., nighttime conditions were not part of the mobile campaign), the entire route was completed, while on a few days the route was covered twice or 1.5 times with the reminder completed the next day. This allowed for multiple samplings of the same locations on different days, times and seasons, but with common days among all locations for key parts of the city (i.e., east Montreal). The goal was to have sufficient measurements spread over days and seasons so as to increase confidence that the longer-term averages derived for any given part of the route and differences between locations were representative of typical conditions. This is assessed in the first part of the results.

The median travel speeds calculated from the GPS were 20, 28 and $30 \mathrm{~km} \mathrm{~h}^{-1}$ for winter, summer and autumn, respectively. Due to these slow traveling speeds, CRUISER was rarely on highways when in such areas and instead tended to drive on service roads parallel to the highways at some distance from the busiest lanes, sometimes with a dividing wall (2-5 $\mathrm{m}$ high) separating the express lanes from the service road. Figure 1c shows that most of the sampling 
Table 1. List of pollutants measured by CRUISER or derived from CRUISER measurements and the methods employed.

\begin{tabular}{|c|c|c|c|c|}
\hline Parameter & $\mathrm{Avl}^{\mathrm{a}} .(\%)$ & Instrument model & Time resolution & Detection limit \\
\hline NO & 80 & Thermo Scientific / TECO 42CTL & $1 \mathrm{~s}$ & $0.4 \mathrm{ppbv}$ \\
\hline $\mathrm{NO}_{2}$ & 64 & Thermo Scientific / TECO 42CTL with photolytic converter & $1 \mathrm{~s}$ & $0.8 \mathrm{ppbv}$ \\
\hline $\mathrm{NO}_{\mathrm{y}}$ & 62 & Thermo Scientific / TECO 42CTL with Mo converter & $1 \mathrm{~s}$ & $0.4 \mathrm{ppbv}$ \\
\hline $\mathrm{NO}_{\mathrm{X}}$ & 64 & Calculated $\left(\mathrm{NO}+\mathrm{NO}_{2}\right)$ & NA & NA \\
\hline $\mathrm{NO}_{\mathrm{z}}$ & 46 & Calculated $\left(\mathrm{NO}_{\mathrm{y}}-\mathrm{NO}_{\mathrm{x}}\right)$ & NA & NA \\
\hline $\mathrm{SO}_{2}$ & 79 & Thermo Scientific / TECO 43 TLE with a $5 \mu$ m pore size Teflon filter & $10 \mathrm{~s}$ & $1 \mathrm{ppbv}$ \\
\hline $\mathrm{CO}$ & 78 & Thermo Scientific / TECO 48 with a $5 \mu \mathrm{m}$ pore size Teflon filter & $10 \mathrm{~s}$ & $100 \mathrm{ppbv}$ \\
\hline $\mathrm{O}_{3}$ & 79 & Thermo Scientific / TECO 49 & $20 \mathrm{~s}$ & $1 \mathrm{ppbv}$ \\
\hline $\mathrm{O}_{\mathrm{x}}$ & 53 & Calculated $\left(\mathrm{NO}_{2}+\mathrm{O}_{3}\right)$ & NA & NA \\
\hline $\mathrm{PM}_{10}$ & 88 & GRIMM dust monitor 1.100 & $6 \mathrm{~s}$ & $0.1 \mu \mathrm{g} \mathrm{m}^{-3}$ \\
\hline $\mathrm{PM}_{2.5}$ & 88 & GRIMM dust monitor 1.100 & $6 \mathrm{~s}$ & $0.1 \mu \mathrm{g} \mathrm{m}^{-3}$ \\
\hline $\mathrm{PM}_{1.0}^{2.0}$ & 88 & GRIMM dust monitor 1.100 & $6 \mathrm{~s}$ & $0.1 \mu \mathrm{g} \mathrm{m}^{-3}$ \\
\hline particle number $(\mathrm{PNC})^{\mathrm{b}}$ & 87 & GRIMM CPC 5.403 & $1 \mathrm{~s}$ & $0.6 \# \mathrm{cc}^{-1}$ \\
\hline $\mathrm{BC}$ (black carbon) & 49 & Droplet Measurement Technologies / Photo Acoustic & $1 \mathrm{~s}^{\mathrm{c}}$ & $<3.3 \mu \mathrm{g} \mathrm{m}^{-3}$ \\
\hline OM (organic matter) & 73 & Aerodyne aerosol mass spectrometer & $2 \mathrm{~min}$ & $0.15 \mu \mathrm{g} \mathrm{m}^{-3}$ \\
\hline Sulfate & 73 & Aerodyne aerosol mass spectrometer & $2 \mathrm{~min}$ & $0.04 \mu \mathrm{g} \mathrm{m}^{-3}$ \\
\hline Nitrate & 73 & Aerodyne aerosol mass spectrometer & $2 \mathrm{~min}$ & $0.02 \mu \mathrm{g} \mathrm{m}^{-3}$ \\
\hline HOA (hydrocarbon-like organic aerosols) & 36 & Aerodyne aerosol mass spectrometer (PMF application ${ }^{d}$ ) & $2 \mathrm{~min}$ & $0.15 \mu \mathrm{g} \mathrm{m}^{-3}$ \\
\hline MZ57 (mass-to-charge ratio of 57) & 36 & Aerodyne aerosol mass spectrometer & $2 \mathrm{~min}$ & $0.01 \mu \mathrm{g} \mathrm{m}^{-3}$ \\
\hline Benzene & 73 & IONICON high-sensitivity PTR-MS & $10 \mathrm{~s}$ & $20 \mathrm{pptv}$ \\
\hline C3-benzene & 73 & IONICON high-sensitivity PTR-MS & $10 \mathrm{~s}$ & $20 \mathrm{pptv}$ \\
\hline Toluene & 73 & IONICON high-sensitivity PTR-MS & $10 \mathrm{~s}$ & 20 pptv \\
\hline Xylene & 73 & IONICON high-sensitivity PTR-MS & $10 \mathrm{~s}$ & 20 pptv \\
\hline
\end{tabular}

availability: percentage of valid measurements from all $1 \mathrm{~s}$ measurements.

b PNC measurements here refers to the commonly named UFP in other studies.

$\mathrm{c}$ Vibrations during mobile measurement result in a poor signal to noise ratio for $1 \mathrm{~s}$ resolution data of the Photo-Acoustic instrument's BC data. However, the analysis presented here aggregates multiple measurements

and thus improves the detection limit. With a $30 \mathrm{~min}$ averaging time the detection limit improves to $0.71 \mu \mathrm{g} \mathrm{m}^{-3}$ and road segment average values used in this paper generally represent averaging over at least $1700 \mathrm{~s}$.

d For more information see Sect. C "Description of the instrumentation inlets to CRUISER" in the Supplement.

was conducted in residential areas, where local traffic was at a minimum, and other areas where the population spends time.

The mobile routine also involved measurements at 17 predefined parking locations (stop sites), such as government AQ monitoring sites. These stationary sites were visited for 10-30 min each time to create a selection of "point samples". Meteorological measurements were only possible during these stationary periods due to the $10 \mathrm{~m}$ height of the telescoping tower. When stopping near a site was not possible (e.g., wind was too stagnant to allow orientation of CRUISER to avoid its own plume), the vehicle drove at slow speeds "circling" the location by driving around the local block. These measurements are referred to as "pseudo-stops" and all data were flagged to note times when CRUISER was stationary, pseudo-stationary or mobile.

There were 11, 17 and 6 mobile measurement days in the winter, summer and autumn, respectively, with $2-13 \mathrm{~h}$ on each day (median of $9 \mathrm{~h}$ ). Figure 1c shows the number of measurements per kilometer of road for the entire campaign; indicating more than 2000 one-second measuring points per kilometer along the predefined route. The greater the number of visits to an area the more representative the available data will be of the long term. Xu et al. (2007) used Canadian monitoring data from multiple cities to show that the number of random visits needed to estimate the long-term average with a desired percent error (e.g., 20\%) depends upon the pollutant. Fewer visits are required for $\mathrm{NO}_{2}$, while more are needed for $\mathrm{NO}$ or CO. About 20 one-hour visits per season are needed to have a $95 \%$ chance of estimating the annual average $\mathrm{NO}_{2}$ with $10 \%$ error.

The eastern route was completed 26 times, of which 11 were in the winter, 14 in the summer and 1 in the autumn. Based upon $\mathrm{Xu}$ et al. (2007) this translates to approximately $95 \%$ confidence that the estimate in annual average $\mathrm{NO}_{2}$ is within $15 \%$ of the actual value for the summer and winter. Actual long-term representativeness is assessed below and, as discussed above, is important. However, it is useful to note that the spatial patterns and particularly the pollutant interrelationships observed are expected to be a reliable representation of the conditions in Montreal given that all locations were visited on the same days and all pollutant measurements were obtained simultaneously. In fact, the spatial patterns shown in this paper are believed to represent an improvement over most other mobile studies of spatial patterns and near-roadway gradients (e.g., Beckerman et al., 2008; Hagler et al., 2010; Massoli et al., 2012) given the large number of measurements for multiple pollutants obtained in a systematic nature on multiple days and at different times in the year across a large, complex city.

\subsection{Comparison to the air quality monitoring network}

Stops and pseudo-stops next to seven different AQ sites (Fig. 1a) were used for comparison between the mobile and routine measurements (i.e., government monitoring network sites). In addition to providing some measure of quality control and assessment of comparability, this was done 
to provide a link between the mobile lab work and the traditional monitoring, such as for obtaining insight into the spatial representativeness of the AQ network site locations. These concurrent, side-by-side measurements were also necessary to be able to quantify the long-term representativeness of the average CRUISER measurements derived from our deployment and data analysis strategy. One-minute readings of $\mathrm{CO}, \mathrm{NO}, \mathrm{NO}_{\mathrm{x}}, \mathrm{SO}_{2}$ and $\mathrm{O}_{3}$ and $1 \mathrm{~h}$ readings of $\mathrm{PM}_{2.5}$ were provided by the local government agency (Ville de Montreal, "VdM") for the periods corresponding to the CRUISER mobile campaign and hourly VdM data were obtained for all other times in 2009. Results of this direct comparison are given in Supplement E.

Two different 2009 VdM annual metrics were calculated to represent the long-term pollution levels: the daily average (i.e., all $24 \mathrm{~h}$ ) and the daytime average (i.e., between 09:00 and 20:00), which better corresponds to the times of day CRUISER was driving. These two long-term metrics are compared to two different short-term averages: (1) the VdM daily averaged values on the days CRUISER took mobile measurements during the nine separate weeks it spent in Montreal and (2) the average of all CRUISER stops and pseudo-stops after eliminating minutes suspected of being impacted by the mobile lab plume. These CRUISER data were first averaged according to visit and then for all visits at an $\mathrm{AQ}$ site so that each visit received equal weight.

\subsection{Spatial analysis}

Since CRUISER's measurements were taken along roads and because of the sharp gradient in concentrations of some pollutants with distance away from the road (e.g., Karner et al., 2010), analysis of the measurements was done by grouping them according to road segment, using ESRI's ArcGIS 9.3 (ESRI, Redland, CA). First, the road network of Montreal was used to extract only the roads CRUISER had visited, so as to avoid attributing measurements to the crossing roads. Then, each of CRUISER's measurement points were assigned to the nearest road segment within a distance of $20 \mathrm{~m}$. Samples were averaged per road segment first by day and then averaged for all days, so as to give an equal weight for every day and avoid bias towards days with more measurements (e.g., greater measurements on a segment due to slower driving speed).

To assure proper representativeness of the measurements at each road segment, only segments that meet the following criteria were used in the analysis: more than 100 valid $1 \mathrm{~s}$ measurements of the examined pollutant, more than 100 valid measurements per kilometer of the examined pollutant and that the measurements were spread over three or more different days. Most road segments included in the analysis were sampled on 17 different days or more. Statistical analysis was done with the open-source statistical language $R$ (RDCT, 2009).

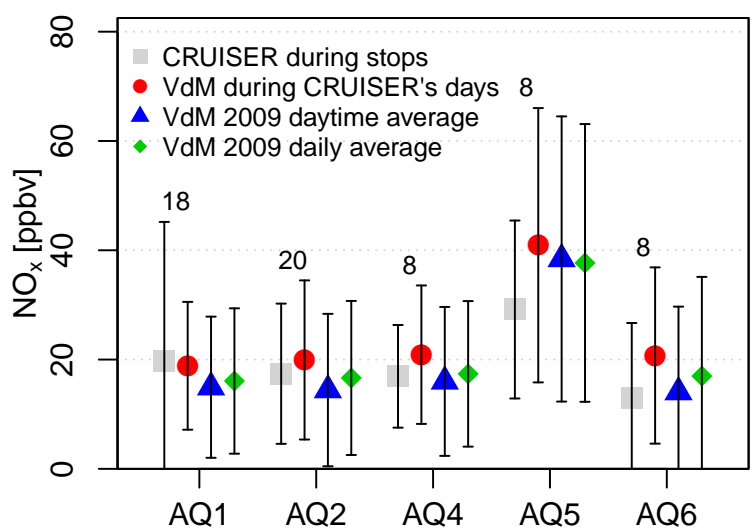

Figure 2. Comparison of CRUISER's average pollution levels during time it was parked next to VdM's AQ monitoring sites (gray squares), VdM's average levels during CRUISER's measurement days (red circles), VdM 2009 daytime annual averages (blue triangles) and VdM 2009 daily annual averages (green diamonds) for seven relevant pollutants. Whiskers denote one standard deviation. Number above whiskers denotes number of visits to site.

Since CRUISER is inherently limited to taking measurements while traveling on roads, an argument can be made that these measurements are limited in that they only represent road emissions and traffic-related pollution and not exposure levels at a home address, which are often used, for example, in health studies. However, for $38 \%$ of the time CRUISER took measurements on local roads in residential areas, where it met few other vehicles and therefore measured ambient residential pollution levels. Similarly, even on busier roads, there were many periods when crosswinds blew the air and pollutants from over the areas adjacent to the road to CRUISER's inlet. This implies that the dominant impact on the mean road segment concentrations was not solely the result of very local emissions associated with nearby traffic, but instead tended to be representative of a realistic mix of these local emissions and general "neighborhood" conditions over that part of the driving route.

\section{Results}

In this section, we first compare the measurements obtained by CRUISER to routine measurements taken by the AQ monitoring network to compare campaign averages to the actual annual average (i.e., to assess representativeness). We then examine the spatial variability of several pollutants at the sub-urban scale with respect to their emission sources and quantitatively examine the representativeness of air quality monitoring sites to various microenvironments in their vicinity. We then compare the rates of decay of several pollutants with distance from a highway based upon campaign-average observations. 
Table 2. Ratios between different average pollution levels shown in Figs. 2 and S1 in the Supplement.

\begin{tabular}{cccccccccc}
\hline & $\begin{array}{c}\text { Ratio type* } \\
N \text { (visits) }\end{array}$ & $\begin{array}{c}\text { AQ3 } \\
21\end{array}$ & $\begin{array}{c}\text { AQ1 } \\
18\end{array}$ & $\begin{array}{c}\text { AQ2 } \\
20\end{array}$ & $\begin{array}{c}\text { AQ4 } \\
8\end{array}$ & $\begin{array}{c}\text { AQ7 } \\
5\end{array}$ & $\begin{array}{c}\text { AQ5 } \\
8\end{array}$ & $\begin{array}{c}\text { AQ6 } \\
8\end{array}$ & Average \\
\hline $\mathrm{NO}_{\mathrm{x}}$ & $\mathrm{C} / \mathrm{D}$ & & 0.93 & 0.87 & 0.92 & & 1.02 & 0.83 & 0.91 \\
& $\mathrm{~B} / \mathrm{D}$ & & 1.17 & 1.20 & 1.20 & & 1.09 & 1.22 & 1.18 \\
& $\mathrm{~A} / \mathrm{D}$ & & 1.23 & 1.05 & 0.97 & & 0.77 & 0.76 & 0.96 \\
$\mathrm{NO}$ & $\mathrm{C} / \mathrm{D}$ & & 1.01 & 0.89 & 0.94 & & 1.06 & 0.81 & 0.94 \\
& $\mathrm{~B} / \mathrm{D}$ & & 1.25 & 1.35 & 1.32 & & 1.12 & 1.37 & 1.28 \\
& $\mathrm{~A} / \mathrm{D}$ & & 2.04 & 1.80 & 1.76 & & 1.64 & 2.69 & 1.99 \\
$\mathrm{NO}_{2}$ & $\mathrm{C} / \mathrm{D}$ & & 0.89 & 0.86 & 0.91 & & 0.98 & 0.84 & 0.89 \\
& $\mathrm{~B} / \mathrm{D}$ & & 1.14 & 1.13 & 1.15 & & 1.05 & 1.15 & 1.12 \\
& $\mathrm{~A} / \mathrm{D}$ & & 0.95 & 0.78 & 0.99 & & 0.68 & 0.65 & 0.81 \\
$\mathrm{O}_{3}$ & $\mathrm{C} / \mathrm{D}$ & 1.19 & 1.20 & & 1.20 & & 1.19 & 1.22 & 1.20 \\
& $\mathrm{~B} / \mathrm{D}$ & 0.79 & 0.81 & & 0.76 & & 0.73 & 0.78 & 0.77 \\
& $\mathrm{~A} / \mathrm{D}$ & 0.88 & 0.99 & & 0.63 & & 0.60 & 0.72 & 0.77 \\
$\mathrm{CO}$ & $\mathrm{C} / \mathrm{D}$ & & 0.94 & & & & 1.08 & 0.90 & 0.98 \\
& $\mathrm{~B} / \mathrm{D}$ & & 1.02 & & & & 1.12 & 1.12 & 1.09 \\
& $\mathrm{~A} / \mathrm{D}$ & & 0.99 & & & & 1.61 & 1.47 & 1.36 \\
$\mathrm{PM}_{2.5}$ & $\mathrm{C} / \mathrm{D}$ & 0.95 & 0.97 & 0.98 & 0.96 & 0.98 & 1.01 & 0.96 & 0.97 \\
& $\mathrm{~B} / \mathrm{D}$ & 1.16 & 1.12 & 1.36 & 1.13 & 1.10 & 1.14 & 1.08 & 1.16 \\
& $\mathrm{~A} / \mathrm{D}$ & 0.95 & 0.70 & 1.06 & 1.36 & 1.64 & 1.27 & 1.14 & 1.16 \\
$\mathrm{SO}_{2}$ & $\mathrm{C} / \mathrm{D}$ & & 1.02 & 0.98 & 0.98 & & & & 1.00 \\
& $\mathrm{~B} / \mathrm{D}$ & & 1.10 & 0.77 & 1.10 & & & & 0.99 \\
& $\mathrm{~A} / \mathrm{D}$ & & 1.37 & 1.56 & 0.99 & & & & 1.31 \\
\hline
\end{tabular}

* A: CRUISER's average during stops; B: VdM's average during CRUISER's measurement days; C: VdM 2009 daytime annual averages; D: VdM 2009 daily annual averages.

\subsection{Representativeness of the mobile measurements}

Although important for mobile surveys to undertake, comparison to AQ network sites is complicated by the fact that there can be differences in the measurement methods used. Results of direct comparisons of concurrent CRUISER and $\mathrm{VdM}$ measurements are described in the Supplement E and here the focus is on assessing long-term representativeness. Figure 2 shows a comparison of CRUISER's mean $\mathrm{NO}_{\mathrm{x}}$ during stops near VdM monitoring sites to VdM's concurrent measurements, to VdM's 2009 daytime averages and to VdM's 2009 daily averages. Ratios of these different metrics are given in Table 2. This one pollutant $\left(\mathrm{NO}_{\mathrm{x}}\right)$ is selected because, due to the methodological differences discussed in Supplement E for each pollutant, the most confident comparison of CRUISER's estimate of the annual average in each area to the actual AQ network values is expected to be based upon $\mathrm{NO}_{\mathrm{x}}$. Comparisons of CRUISER vs. the VdM 2009 averages for the other pollutants are shown in Fig. S1 in the Supplement.

The VdM average among all the driving days was calculated to determine whether, collectively, the driving days in each season were atypical of the annual averages (ratios C / D and $\mathrm{B} / \mathrm{D}$ in Table 2). Table 2 shows that on the selected driving days $\mathrm{NO}_{\mathrm{x}}$ tended to be higher on average by $18 \%$ compared to the 2009 daily averages. However, the overall ranking among the sites during these days was similar to the annual pattern (Fig. 2). For the other pollutants ( $\mathrm{CO}$, $\mathrm{PM}_{2.5}, \mathrm{SO}_{2}, \mathrm{O}_{3}, \mathrm{NO}$ and $\mathrm{NO}_{2}$ ), the average differences between the study period $\mathrm{VdM}$ observations and the annual average among the sites with measurements were $9,16,-1$, $-23,28$ and $12 \%$, respectively (Table 2 ). Thus average concentrations on the days that the mobile measurements were conducted tended to be biased high compared to the 2009 average, except $\mathrm{O}_{3}$, which was biased low. However, in terms of combustion pollutant levels $\left(\mathrm{NO}_{\mathrm{x}}\right)$, the average high bias was $18 \%$ for the period, while for $\mathrm{NO}_{2}$, which is often of most interest as an exposure indicator, the bias was smaller, at $12 \%$.

CRUISER's deployment strategy of limited but random collection of daytime measurements at and around each VdM site also tended to yield reasonably representative values for $\mathrm{NO}_{\mathrm{x}}$. Table 2 shows the ratio of CRUISER's estimates to the 2009 daily average (ratio type A/D) was between 23 and $-24 \%$. Furthermore, despite even fewer measurements at AQ5, CRUISER's campaign-average observations correctly identified this site as having the highest $\mathrm{NO}_{\mathrm{x}}$. Consistent with the 2009 average pattern, CRUISER also showed that the variability among all sites except AQ5 was relatively small. However, CRUISER observed a greater variability than tended to exist. Further focusing on the two VdM sites measuring $\mathrm{NO}_{\mathrm{x}}$ where there were $>18$ visits, which corresponds to the survey in east Montreal, the observed range was 16.1-16.6 ppbv (2009 daily average) and CRUISER reported 


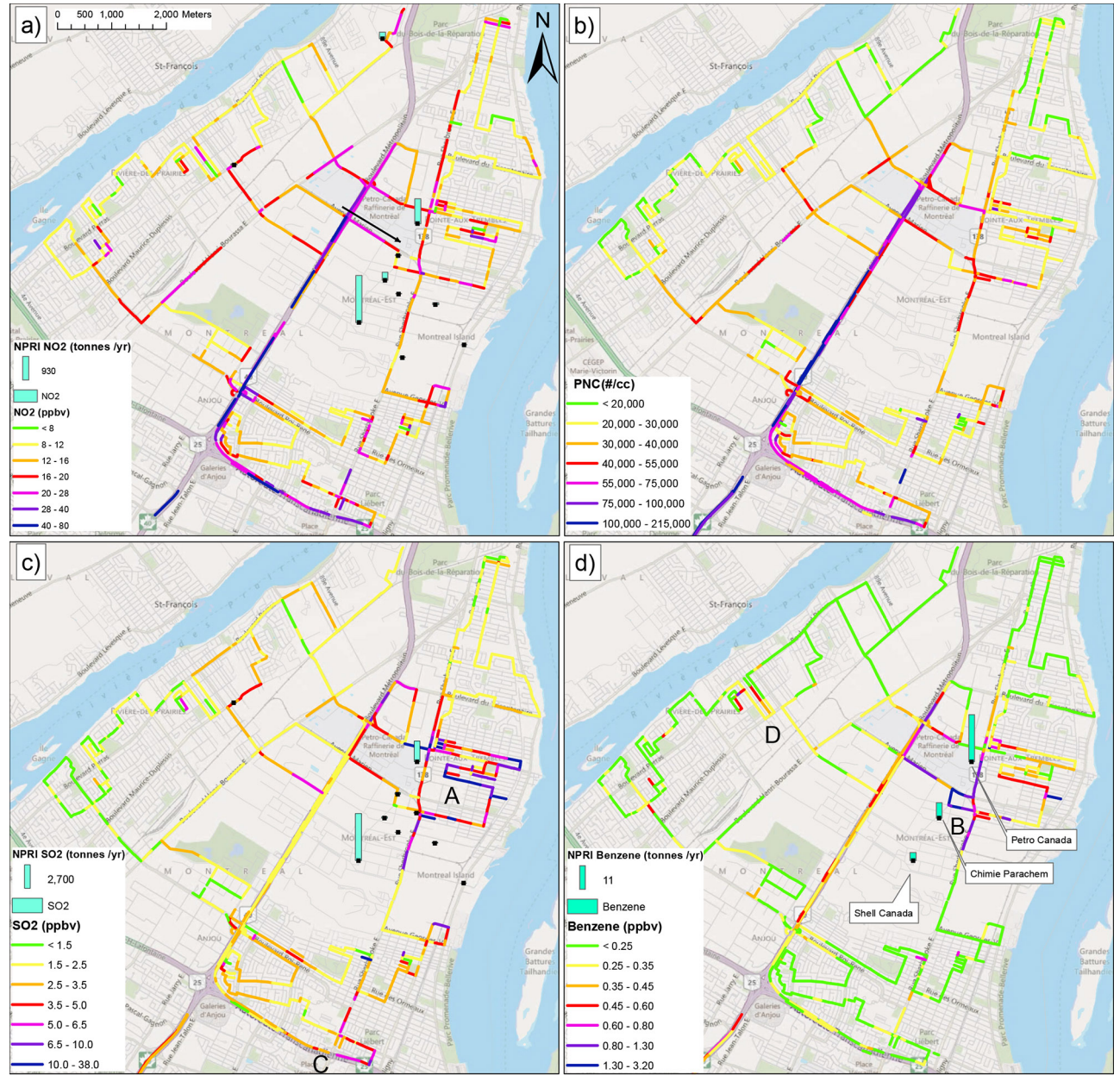

Figure 3. Mean pollution levels for the entire study at road segments for $\mathrm{NO}_{2}$ (a), $\mathrm{PNC}$ (b), $\mathrm{SO}_{2}$ (c) and benzene (d), along with National Pollutant Release Inventory (NPRI) reported point emissions for the relevant pollutants. Roads were filtered as described in Sect. 2.4. NPRI emissions for $\mathrm{NO}_{2}$ are nitrogen oxides expressed as $\mathrm{NO}_{2}$.

a 17.4-19.8 ppbv range. Information on the differences between CRUISER short-term estimates of the average and the actual 2009 average for the other pollutants is shown in Fig. S1. These comparisons should be interpreted with caution, however, given the measurement method differences discussed in Supplement $\mathrm{E}$ and the overarching issue of limited data at most sites except $2-3$ in the east. Figure S1 shows, for example, that CRUISER was within $20 \%$ on average for $\mathrm{NO}_{2}$. This is reasonably close, but $5 \%$ less accurate than the expected error upon Xu et al., (2007). As expected, for the sites only visited eight times, the CRUISER longer-term average $\mathrm{NO}_{2}$ estimate was biased low by up to $35 \%$ compared to the true annual average.

\subsection{Intra-urban variability observed by CRUISER}

The multiple pollutant measurements on CRUISER allowed for focus on differences in campaign-average spatial patterns among pollutants. This is exemplified for four pollu- tants $\left(\mathrm{NO}_{2}\right.$, particle number concentration (PNC), $\mathrm{SO}_{2}$ and benzene) in the east Montreal maps shown in Fig. 3. Trafficrelated pollutants, such as $\mathrm{NO}_{2}$ and $\mathrm{PNC}$, show highest concentrations near the highways (e.g., $\mathrm{NO}_{2}$ mixing ratios of up to $80 \mathrm{ppbv}$ and PNC counts of up to $215000 \# \mathrm{cc}^{-1}$ near highways 40 and 25 shown in Fig. 3a and b). Lower concentrations were measured on major roads (12-28 ppbv $\mathrm{NO}_{2}$ and 30000-55 $000 \mathrm{\#} \mathrm{cc}^{-1} \mathrm{PNC}$ ) and the lowest in residential areas $\left(<12\right.$ ppbv $\mathrm{NO}_{2}$ and $\left.<30000 \# \mathrm{cc}^{-1} \mathrm{PNC}\right)$. These differences are consistent with the reported emissions for Quebec in 2007, that the transportation sector accounted for $74 \%$ of $\mathrm{NO}_{\mathrm{x}}$ emissions, compared to $15 \%$ from industrial sources, including $2 \%$ from oil refineries (Busque et al., 2009).

Other pollutants that have a significant contribution from industrial emission sources, such as $\mathrm{SO}_{2}$ and benzene, show a different intra-urban spatial pattern, with high concentrations around the industrialized eastern part of the city between highways 40 and 138 (Fig. 3c and d, respectively; roads identified in Fig. 1b). For $\mathrm{SO}_{2}$, Busque et al. (2009) report 


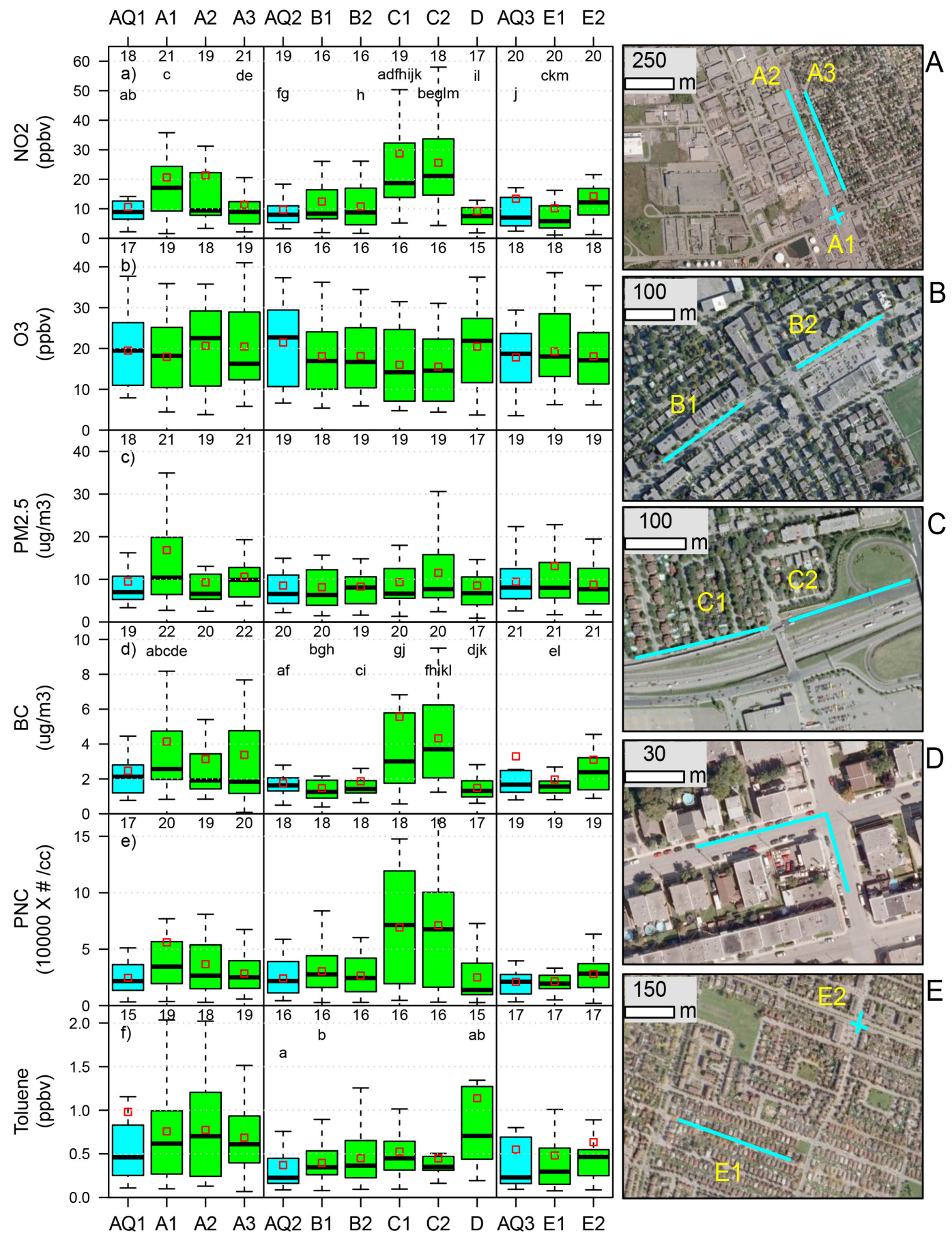

Figure 4. Box plots showing pollutant levels $\left(\mathrm{NO}_{2}, \mathrm{O}_{3}, \mathrm{PM}_{2.5}, \mathrm{BC}\right.$, $\mathrm{PNC}$ and toluene; (a-f), respectively) at 10 different areas (green) compared to measurements taken next to three air quality monitoring sites (blue). Red squares are the mean and numbers above each box mark the number of days included in the statistics. The panels in the right-hand column show local settings of each area marked in blue (A-E). See Fig. 1b for locations within the city.

that, provincially, transportation accounted for only $11 \%$, compared to $7 \%$ from the oil refineries, with the aluminum smelters contributing $30 \%$ and other industrial sources contributing $24 \%$. With no aluminum smelters on the Island of Montreal and transportation being spread over the entire road network, oil refineries and other industrial point sources have a dominant contribution to $\mathrm{SO}_{2}$ as is seen in Fig. 3c. Benzene emissions are not reported independently in Busque et al. (2009); however for volatile organic compounds (VOCs) 
transportation accounted for $37 \%$, gasoline and diesel marketing for $5 \%$ and other industries for $27 \%$.

Sulfur dioxide and VOCs such as benzene are of interest in east Montreal given their link to the refining and petrochemical industries. The mobile measurements indicate that even though broad similarities for these two pollutants are evident over the urban scale shown in Fig. 3, there are differences in their behavior on smaller scales. For example, the peak area with $\mathrm{SO}_{2}$ concentrations (marked A in Fig. 3c) is located further northeast than the benzene peak area (marked $\mathrm{B}$ in Fig. 3d). Also, the area of elevated $\mathrm{SO}_{2}$ identified as " $\mathrm{C}$ " is not accompanied by higher benzene. Instead, this area appears to be accompanied by higher $\mathrm{NO}_{2}$. These elevated campaign-average concentrations are hypothesized to be indicative of the influence of ship emissions and/or diesel trucks servicing one of the port areas, given the proximity of this portion of the driving route to the St. Lawrence River and the large port area for container ships. Apart from the four pollutants described above, spatial patterns of all the other pollutants measured on this study were evaluated (not shown) and have been used in subsequent analyses (Brook et al., 2013; Levy et al., 2014). Spatial differences are examined further based upon urban micro-environment and distance from the highway in the next section below.

Levy et al (2014) reported on the spatial correlations among all the parameters measured across Montreal, highlighting which pollutants tend to covary and which are associated with different sources. From Fig. 3 and Levy et al. (2014) it can be seen that some mixes of pollutants show affinity to roads (BC, $\mathrm{CO}, \mathrm{HOA}, \mathrm{NO}, \mathrm{NO}_{\mathrm{x}}, \mathrm{OM}, \mathrm{PM}_{1}, \mathrm{PM}_{2.5}$, $\left.\mathrm{PM}_{10}, \mathrm{PNC}\right)$ and others are related to industry $\left(\mathrm{SO}_{2}\right.$, toluene, xylene). Clearly, a range of interesting features related to sources and potentially more relevant to chronic exposures are revealed through CRUISER's deployment approach. Another example is the port area mentioned above (high $\mathrm{SO}_{2}$ and $\mathrm{NO}_{2}$ ). However, describing in detail how the multipollutant mix associated with the large number of potential sources varies is beyond the scope of this paper. Furthermore, the behavior of the mixtures varies on multiple spatial scales, each requiring follow-up analysis. For example, differences in the variation in $\mathrm{SO}_{2}$ and benzene concentrations along a single road crossing Highway 40 and passing next to the Petro-Canada oil refinery to the north and the Ultramar oil distribution terminal to the south (Avenue Marien, location shown by arrow in Fig. 3a) shows that some peaks in concentration occur together while others do not (Fig. S2). Furthermore, ratios of toluene to benzene in the peaks and between peaks also vary. These small-scale differences are indicative of how different processes within a single large industrial facility (refinery) may differentially impact surrounding locations with systematically different pollutant mixtures.

\subsection{Microenvironments and sub-neighborhood-scale variability}

In order to characterize the extent that chronic exposure levels can vary among a range of typical settings in an urban environment, 10 small east Montreal areas that were visited by CRUISER were selected and compared (Fig. 4). The distributions of the campaign averages among these different settings are also compared to measurements taken by CRUISER when at the nearest AQ site during stops and pseudo-stops. These sites are included in Fig. 4 to provide insight into the representativeness of the monitoring site locations and hence the possible error or bias resulting from assigning or modeling chronic exposure estimates based only upon available monitoring network data.

The 10 areas were selected so that they represent a range of urban microenvironments while also being relatively close in proximity to one another, thus reflecting the activity space over which individuals might typically travel, especially children and the elderly. Their locations within the city are shown in Fig. 1b, labeled as A-E, and in greater detail in Fig. 4. The areas selected include the intersection of two main roads Rue Sherbrooke East and Blv. St-Jean-Baptiste (A1); an active commercial area on Rue Sherbrooke East (A2) near A1; and a residential street (Rue Forsyth) $\sim 80 \mathrm{~m}$ east and parallel to A2 (A3). These are located on the east side of the island in proximity to the oil refineries and are compared to the nearest monitoring site (AQ1, within $1.2 \mathrm{~km}$ of all these areas).

In the middle of Fig. 4, another grouping of sites is shown in comparison to their local monitoring site (AQ2), at distances of $0.7-1.0 \mathrm{~km}$. The settings for these five areas are as follows: a moderately busy road in a residential area (Anjou) next to houses (B1); a section of the same road next to an active commercial area (B2); a local road in a residential area next to a service road and a busy highway (HW-15), but with a noise-blocking wall separating the highway and the service road from the local road (C1); near an exit ramp of the local major highway (HW-15) bordering the residential area without a noise-blocking wall (C2); and a street corner in a residential area with a small car repair shop (D) in Anjou. The pair B1 and B2 is located east of the busy interchange of highways 40 and 25.

The last grouping of microenvironments, shown on the right side of Fig. 4, corresponds to monitoring site AQ3 at a distance of $2 \mathrm{~km}$ or less. These two areas are located west of the other areas and are generally upwind from the major stationary emission sources and traffic corridors and include a residential street (E1) and an intersection of two local roads (E2) some $500 \mathrm{~m}$ from E1.

Each area in Fig. 4, as well as the AQ sites, were visited an equal number of times, mostly on the same days and in all seasons. The distributions in Fig. 4 show all of CRUISER's measurements for these periods, first averaged by day and then presented in box plots for all days for 
different pollutants. Visually, differences in the levels among the areas are evident. Significant differences between the areas were assessed for each pollutant separately by the nonparametric Kruskal-Wallis test followed by the Wilcoxon rank-sum test for pairwise group comparisons. Areas with a similar letter are significantly different $(p$ value $<0.05)$. Based only upon the distributions of the values averaged by day for each location, the differences were only significant for $\mathrm{NO}_{2}$ and $\mathrm{BC}$. However, due to the small sample size for these tests $(<20$ days) the analysis was repeated with the actual $1 \mathrm{~s}$ data. As shown in Fig. S3, many more significant differences are detectable for all pollutants examined using the higher-resolution data.

The mean $\mathrm{NO}_{2}$ mixing ratios (red squares in Fig. 4) at the traffic-affected areas A1 and A2 are double that of the $10 \mathrm{ppbv}$ measured next to the nearest monitoring site, AQ1, while the residential area $\mathrm{A} 3$ has mixing ratios similar to AQ1. This indicates that the monitoring site underestimates the exposure levels for A1 and A2 while providing a representative estimate for $\mathrm{A} 3$. $\mathrm{AQ} 1$ also underrepresents $\mathrm{PM}_{2.5}$, $\mathrm{BC}$ and $\mathrm{PNC}$ for $\mathrm{A} 1$ when examining both the median (A1 is higher by 49,21 and $60 \%$, respectively) and mean (A1 is higher by 78,68 and $128 \%$, respectively). Comparing the busy intersection $\mathrm{A} 1$ with the active commercial area $\mathrm{A} 2$ and the residential street $\mathrm{A} 3$, concentrations of $\mathrm{NO}_{2}$ are higher for A1 than A2 and for A2 than A3 (Fig. 4a), as can be expected given the characteristics of those areas. The same differences in the distributions are also seen for PNC for these three areas (Fig. 4e).

$\mathrm{NO}_{2}$ measurements next to the main road microenvironment at $\mathrm{C} 1$ and $\mathrm{C} 2$ are considerably higher than the monitoring site AQ2 with the median (mean) higher by 10 and 14 ppbv, respectively (20 and $16 \mathrm{ppbv}$, respectively), an increase of $210-265 \%$. Ozone at $\mathrm{C} 1$ and $\mathrm{C} 2$ shows a corresponding decrease of $32 \%$ from $\mathrm{AQ} 2$ levels. $\mathrm{BC}$ and $\mathrm{PNC}$ also have higher concentrations at $\mathrm{C} 1$ and $\mathrm{C} 2$ compared to AQ2 of more than $180 \%$ for the median and $200 \%$ for the mean of $\mathrm{BC}$ and $300 \%$ for both mean and median of PNC. The mean $\mathrm{PM}_{2.5}$ next to $\mathrm{C} 2$ is also higher than AQ2 by about $20 \%$, providing evidence of its spatial variability. The resemblance between $\mathrm{C} 1$ and $\mathrm{C} 2$ for these pollutants, however, implies that, on average, the noise-blocking wall in $\mathrm{C} 1$ has little effect on air pollution. Comparing areas E1 and $\mathrm{E} 2$, higher values of $\mathrm{NO}_{2}$ (13.6 vs. 9.4 ppbv), $\mathrm{BC}$ (3.1 vs. $\left.2.0 \mu \mathrm{g} \mathrm{m}^{-3}\right)$, PNC (27950 vs. $21575 \mathrm{Acc}^{-1}$ ) and toluene ( 0.63 vs. $0.48 \mathrm{ppbv})$ and lower $\mathrm{O}_{3}(18.1$ vs. $19.3 \mathrm{ppbv})$ are measured at the intersection area of E2 compared to the residential area E1 near it. Clearly, any time spent at such an urban microenvironment enhances exposure and leads to greater misclassification if exposure is assigned according to the nearest AQ site.

Lastly, area D shows similar values to what is measured next to the monitoring site AQ2 for most pollutants, with the exception of toluene. The presence of a small paint and body shop in that area caused the high values of this organic compound with a mean of 1.14 ppbv. Toluene levels in this localized microenvironment were 2-3 times higher than at the nearby monitoring site AQ2 (0.37 ppbv) and compared to the nearby areas B1, B2, C1 and C2 $(0.40,0.45,0.53$ and $0.45 \mathrm{ppbv}$, respectively). The levels were even somewhat higher than the mean measured at areas A1-A3 (0.76, 0.78 and $0.69 \mathrm{ppbv}$, respectively) and the monitoring site AQ1 (0.98 ppbv), which are in closer proximity to the petroleum facility. The difference between area D and the others for toluene is much higher in the summer season (not shown), probably due to greater evaporation of this compound in higher temperatures and the fact that the shop more often operated with open doors in the summer.

\subsection{The impact of a busy highway: near road to deep into residential areas}

The comparisons shown in Fig. 4 provide some information on the increase in concentrations associated with proximity to traffic. To more directly assess how the presence of a major highway impacts multipollutant exposure within an adjacent neighborhood, the measurements along a $1200 \mathrm{~m}$ cross section perpendicular to Highway 40 in Anjou were isolated for further study. The observations start at a service road running parallel to Highway 40 and continue along Avenue Azilda (a one way street in a residential area with little traffic), as shown by an arrow in Fig. 1e. This cross section was sampled at different times of the day on 15 separate passes in the summer, 9 in the winter and 2 in the autumn, and includes varying wind conditions (i.e., measurement periods were not selected to always represent downwind conditions, although prevailing wind does place Avenue Azilda downwind more often than upwind). Measurements along this cross section for the whole campaign were aggregated according to $20 \mathrm{~m}$ bins and the median and inter-quartile range (IQR) per bin are plotted according to distance from the center of Highway 40 in Fig. 5. Along this cross section there were occasional streets crossing perpendicular to Avenue Azilda and these are indicated by arrows across the top of the figure. We also added the mean of all measurements taken on the highway (east and west bound combined) as a point marker for indicating the on-road values, though these are not co-measured with the cross-section measurements. Also shown for comparison (blue lines in Fig. 5) is the synthesis of 41 studies of near-road gradients presented by Karner et al. (2010) and (in black lines) spline smooth-curve fits to the CRUISER median concentrations in order to remove small-scale variability and help reveal the shape of the observed decreases in concentration.

With the exception of ozone, all pollutants in Fig. 5 show a decrease in concentration away from the highway for the campaign average. Some pollutants show a rapid decrease of more than $60 \%$ within a few tens of meters (i.e., decreases of $85,83,63$ and $60 \%$ for NO, PNC, BC and CO, respectively, after $70 \mathrm{~m}$ ), while others show a more moderate trend (i.e., 
decreases of 50, 43, 55, 30 and $30 \%$ for $\mathrm{NO}_{2}, \mathrm{PM}_{2.5}, \mathrm{PM}_{10}$, HOA (combustion-related organic $\mathrm{PM}_{1.0}$ ) and benzene, respectively, after $70 \mathrm{~m}$ ). There appears to be some contribution from emissions in the vicinity of the first cross street although the amount of traffic on this street was much less than the highway and service road. After adjustment to the edge of road values measured by CRUISER, these decreases and the curve fits are in general agreement with Karner et al. (2010) for most pollutants (NO, PNC, BC and CO). However, CRUISER's measurements did tend to show a more rapid change.

For particulate matter $\left(\mathrm{PM}_{2.5}\right.$ and $\left.\mathrm{PM}_{10}\right)$ the gradients measured by CRUISER are greater than what is shown by Karner et al. (2010). Even though a sharp near-road gradient in PM was observed in the summer (not shown), the main contribution to the sharp drop in the campaign-average data is the elevated particles measured near Highway 40 in the winter (not shown) in Montreal. On average, $\mathrm{PM}_{2.5}$ doubled from the neighborhood background to the near-highway environment, while HOA, a component of $\mathrm{PM}_{2.5}$ which is expected to be a more specific measure related to traffic fine particles (Sun et al., 2012), more than tripled in magnitude (see Fig. 6 described later).

There is evidence in the cross-section plots that some pollutants (i.e., $\mathrm{NO}_{2}, \mathrm{CO}$ and $\mathrm{HOA}$ ) remain slightly elevated above the background up to $\sim 700 \mathrm{~m}$ from the highway. This was much more evident among the winter measurements, although they are not shown here given this paper's focus on longer-term, average pollutant patterns. The maximum distance of the potential highway impact was further examined by calculating the normalized cross sections relative to the neighborhood background levels, assumed to be represented by the concentrations at $1000-1500 \mathrm{~m}$ away, which is where the levels reached a minimum and showed no evidence of increasing or decreasing (Fig. 6). The bins used in Fig. 6 include the highway from $20 \mathrm{~m}$ west of the highway center to $20 \mathrm{~m}$ east, accounting for the measurements on the highway from separate visits traveling east and west bound up to a dividing acoustic wall ( $3 \mathrm{~m}$ high) separating it from the parallel service road. The bins continue with separate $50 \mathrm{~m}$ bins (i.e., 20-70 m, 70-120 m, etc.) from the service road and along the transect on Avenue Azilda.

$\mathrm{CO}$ was observed to decrease consistently to the background concentration at about $600 \mathrm{~m}$ from the highway, while $\mathrm{NO}_{2}$ and HOA both appear to reach the background further away at about $700 \mathrm{~m}$. There is an increase in some pollutants around $360 \mathrm{~m}$ from the highway which is most noticeable for $\mathrm{NO}, \mathrm{PM}_{2.5}$ and $\mathrm{BC}$ (Fig. 5b, e and g, respectively) and is associated with a decrease in $\mathrm{O}_{3}$ (Fig. 5c). This is likely due to the contribution of the crossing road at that location, thus providing some insight into the potential impact smaller roads can have on exposure. Although the other crossing roads were not observed to have such an effect, it is likely that the road at $360 \mathrm{~m}$ contributed somewhat to the pollutant levels further downwind on some days. For $\mathrm{NO}_{2}$ the el-

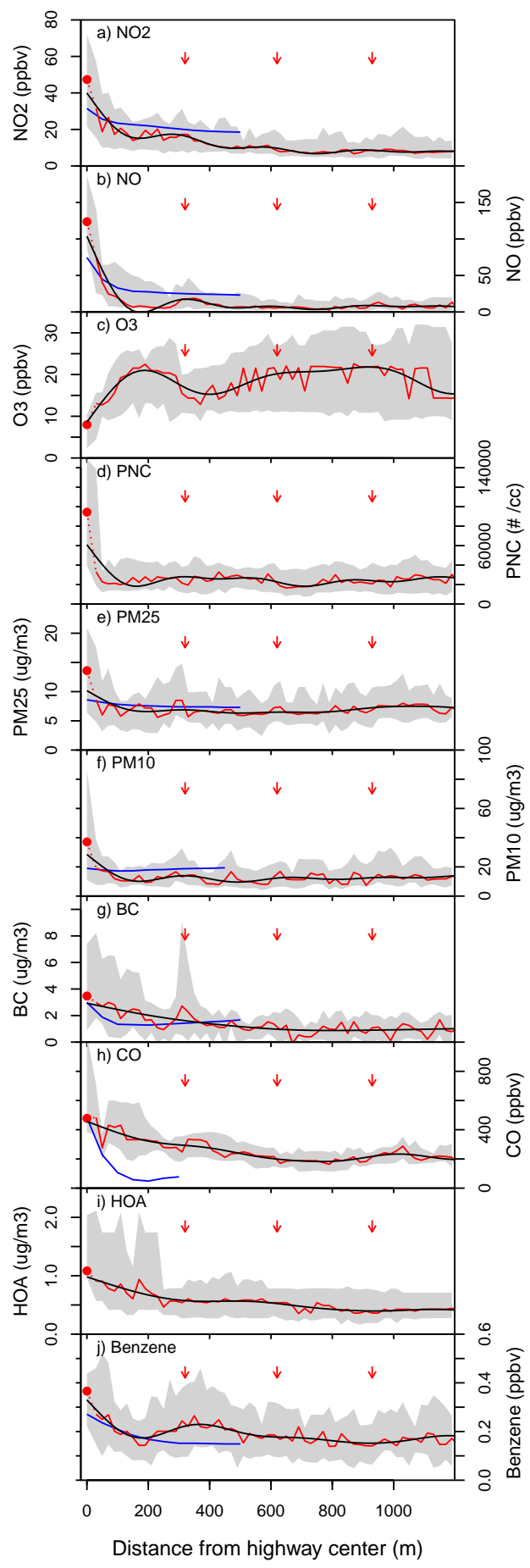

Figure 5. Median pollution levels (red line) and IQR (gray) at $20 \mathrm{~m}$ bins for the entire study, showing $\mathrm{NO}_{2}, \mathrm{NO}, \mathrm{O}_{3}, \mathrm{PNC}, \mathrm{PM}_{2.5}, \mathrm{BC}$, $\mathrm{CO}$, traffic-related $\mathrm{PM}_{1}(\mathrm{HOA})$ and benzene along the cross section marked in Fig. 2d. Arrows mark the locations of perpendicular roads meeting the cross section. Blue lines show the change in pollution from the edge of the road based on Fig. 3 from Karner (2010) and adjusted to CRUISER's measurements at the edge of the road to facilitate comparison. Black lines are a spline smoothing of the measurements. Red points mark measurements taken passing through the highway. 


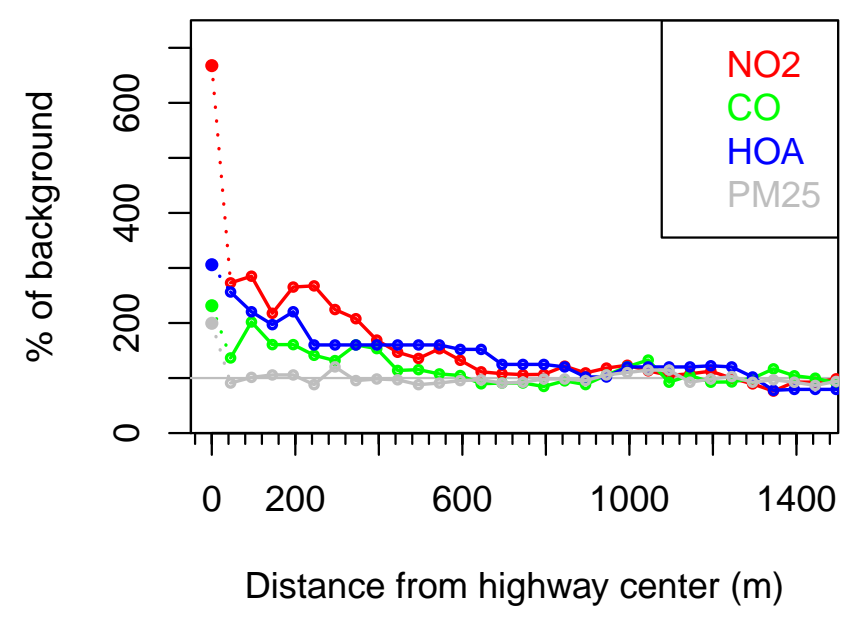

Figure 6. Normalized cross sections of $\mathrm{NO}_{2}, \mathrm{CO}, \mathrm{HOA}$ and $\mathrm{PM}_{2.5}$ along the cross section described in the text and Fig. 5. Calculated as the median at each distance divided by the average of the 10001500 m medians. Leftmost points at distance 0 mark measurements taken passing through the highway.

evated levels observed by CRUISER up to $700 \mathrm{~m}$ (Fig. 5a) are supported in the synthesis presented by Karner et al. (2010). Their synthesis shows that $\mathrm{NO}_{2}$ is gradually reducing up to at least $500 \mathrm{~m}$ where their data end, but still appearing to decrease thereafter. The similarity between the decrease in $\mathrm{NO}_{2}$ and HOA suggests a link between $\mathrm{NO}_{2}$ and the organic fraction of fresh traffic-related particles.

Scale-up factors (i.e., percentages of increase relative to the neighborhood background levels) for multiple pollutants were calculated as a function of distance away from the highway center as described above for Fig. 6. These scale-up factors, which may enable estimates of typical near-road levels relative to urban background monitoring sites, are tabulated in Supplement Table S1. The factors include in them the apparent contribution of the crossing roads which (mainly the first) appeared to have a stronger effect on $\mathrm{NO}, \mathrm{O}_{3}, \mathrm{BC}$ and benzene.

\section{Discussion}

In this study, strategic short-term measurements taken with a mobile lab were compared both to the concurrent measurements at AQ monitoring sites in Montreal and to the annual averages at these sites to assess representativeness of the average concentrations derived from the mobile lab deployment. Determining how well a limited set of mobile lab measurements spread among three seasons captures the true long-term pattern is complicated due to the fact that it is necessary to rely on the existing monitoring sites to determine the long-term value. However, there are only a limited number of monitoring sites, which are often in urban background locations. For such sites measurement methods are not the same as the mobile lab due to different technical requirements. Moreover, the mobile lab is not always able to measure right next to the sample inlets at the sites. Despite these limitations, we compared the averages of the short-term (from CRUISER and the corresponding day's $24 \mathrm{~h}$ data from VdM) and 2009 daily and daytime average values at a number of sites. Overall, except for $\mathrm{O}_{3}$, the study measurement days were found to have experienced higher than average pollutant levels. For example, $\mathrm{NO}_{\mathrm{x}}$, which is a good indicator of urban combustion pollution, was higher on average by $18 \%$, compared to the 2009 daily average. Averages derived from CRUISER's systematic visits of generally one per day spread through three seasons were within $\pm 24 \%$ of the 2009 daily average, thus only increasing the discrepancy by $6 \%$ despite considerably fewer data points.

Identification of the AQ sites with notably higher vs. lower annual average concentrations was generally possible with the limited number of mobile lab visits. For example, both CRUISER's observations and the VdM data during the corresponding period correctly identified the location (AQ site) with the highest $\mathrm{NO}_{\mathrm{x}}$ levels, thus providing evidence that major concentration gradients across the city can be quantified through a systematic deployment approach. However, there were discrepancies, particularly when the differences between the long-term values at the sites were small. For example, the 2009 mean $\mathrm{NO}_{\mathrm{x}}$ at four of the five sites visited only differed by approximately $1.3 \mathrm{ppb}$. Not surprisingly, the short-term visits are not able to achieve the precision in their estimate of the annual average to similarly rank these sites within such a small overall concentration range. However, for characterizing spatial gradients and chronic exposure levels, and also for exposure model development, detecting such small differences is less important than capturing the larger exposure differences that exist among various areas. While it is not surprising that $\mathrm{AQ}$ sites generally do not document the full exposure gradients, this also means that they are of less use for assessing whether the exposure gradients captured by a short-term mobile lab survey are indicative of the true longterm pattern.

Campaign-average concentrations derived from CRUISER have provided a better picture of multipollutant spatial patterns and correlations (Levy et al., 2014) across multiple scales. They reveal systematic differences between neighborhoods in the pollutant levels and in the characteristics of the multipollutant mixture that are related to variations in sources. The relatively large spatial coverage that mobile monitoring can provide also helps uncover changes in concentrations on very small scales and can even identify and characterize concentration hotspots resulting from small businesses operating in residential areas (e.g., dry cleaners, car repair shop or a restaurant), from commercial areas and from intersections in a residential neighborhood. Such small-scale variations may result in large differences in exposures to air pollutants among the population, yet they are often not included in air quality models or other exposure 
models because of lack of detailed knowledge about the location and type of activity of small emitters or due to their small emission volumes compared to other major sources or inaccurate traffic data. Furthermore, our results show that local emitters may have an impact on a local scale that can be greater than that of major sources further away, even in comparison to levels closer to such sources.

The identification of unknown local air pollution hotspots is impossible with traditional measuring techniques (i.e., stationary AQ monitors), given that measuring sites are selected to either measure ambient levels or examine previously known emission sources. The ability to identify smallscale emission sources and exposure hotspots with mobile measurements has been previously demonstrated (e.g., Fujita et al., 2013; Larson et al., 2007; Spengler et al., 2011). For example, Dionisio et al. (2010) showed that measurements of $\mathrm{PM}_{2.5}$ and $\mathrm{PM}_{10}$ at stop sites with multiple woodstoves were 30 and $85 \mu \mathrm{g} \mathrm{m}^{-3}$, respectively, higher than the neighborhood average at the same times in a study in Accra, Ghana. Larson et al. (2007) also obtained a more detailed understanding of areas with higher exposures to woodsmoke emissions through mobile measurements in the Vancouver area. Levy et al. (2001) showed some evidence of elevated $\mathrm{PM}_{2.5}$ near diesel buses in a walking-mobile measurements study in Roxbury, Massachusetts, United States. Apart from the mobility aspect of these campaigns, which allows them to cover larger spatial domains, another advantage of mobile measurements is that they typically use shorter averaging times for the measurements of few seconds to few minutes (e.g., $1 \mathrm{~s}$ in this study and $1 \mathrm{~min}$ by Levy et al., 2001). This enables them to map fine spatial structures needed to identify hotspots.

Mobile labs are also a particularly useful platform for measuring spatial gradients in concentrations relative to sources and to study small-scale processes. In this study, average CRUISER measurements from 26 independent days taken perpendicular to Highway 40 through a residential area have led to new insight into chronic exposure gradients. While all pollutants (with the exception of ozone) decrease in concentrations away from the highway, the rate of decrease differs by pollutant, as does the distance that they spread into the adjacent neighborhood. For several pollutants (i.e., $\mathrm{NO}_{2}, \mathrm{CO}$ and HOA) there is evidence in our measurements that, on average, they remain elevated above the background for up to $700 \mathrm{~m}$. It should be noted that in Anjou some additional emissions (i.e., crossroads) may have played a role in the CRUISER observations, but these were relatively small compared to the highway. With HOA being associated with traffic fine particles (Canagaratna et al., 2010), this may hint at one reason why $\mathrm{NO}_{2}$ has often been used successfully as a traffic exposure indicator in assessing traffic-related health effects (e.g., Crouse et al., 2010; Jerrett et al., 2009). Firstly, the elevated $\mathrm{NO}_{2}$ associated with a traffic source affects a larger percentage of the neighborhood compared to some pollutants (e.g., PNC and NO). Secondly, if this greater extent of higher
$\mathrm{NO}_{2}$ is also accompanied by higher $\mathrm{CO}$ and HOA (and possibly other unmeasured pollutants such as trace metals or other more toxic organic particles) up to $700 \mathrm{~m}$ from a highway, then the effects attributed to $\mathrm{NO}_{2}$ are possibly due to these and other similarly behaving pollutants and/or some or all of the mixture of particles and gases.

Greater spread of traffic particles has been observed elsewhere under certain conditions (e.g., Hu et al., 2009). Similarly, in Montreal, it was wintertime conditions that favored a greater spread of air pollutants (not shown), which was likely due to lower mixing heights and longer lifetimes of some pollutants due to less evaporation (i.e., colder temperatures) and/or less photochemistry. Even though the measurements were obtained from multiple days and seasons, which has rarely been done, the prevalence of the behavior observed by CRUISER in the Anjou neighborhood of Montreal and its relevance to other areas is unknown, and thus some followup study should be considered to strengthen their value to exposure model development and possibly to guide urban planning. Nonetheless, here we have reported average concentration scale-up factors relative to urban background in Montreal as a function of distance from the highway as a potential first step in generalization to support future use.

Due to its relatively long lifetime in the atmosphere, PM is generally considered to be spatially homogeneous over distances of a few kilometers (e.g., Martuzevicius et al., 2004), although Beckerman et al. (2008) have shown significant increases close to a major highway in Toronto. Here we also show that $\mathrm{PM}_{2.5}$ and $\mathrm{PM}_{10}$ are affected by proximity to roads. This is also reflected by two important $\mathrm{PM}_{2.5}$ constituents: BC and HOA. The impact of the highway was particularly evident in the winter, when higher concentrations were measured up to $370 \mathrm{~m}$ away due to the combined effect of a more stable atmosphere near the ground (Bergeron and Strachan, 2012) and the use of road salt and sand for tire traction (Gertler et al., 2006). However, compared to the other pollutants explored in this paper and in Levy et al. (2014) average $\mathrm{PM}_{2.5}$ concentrations were, overall, more homogeneous and, with the exception of near the highways, the observed peak concentrations appeared to be localized, shortlived and difficult to explain in terms of their source(s).

The capabilities of physically based models to determine urban spatial patterns have improved in recent years. For example, the ability of comprehensive, multipollutant air quality models to run for longer periods at grid resolutions of $1-5 \mathrm{~km}$ is increasing (e.g., Makar et al., 2010; Shrestha et al., 2009). Output from these higher-resolution models may eventually lead to multipollutant information relevant to chronic exposure estimation. However, as shown in this paper and most other mobile lab studies, there remains a large and complex variability even within the finest model grids (at best $\sim 1 \mathrm{~km}^{2}$ area) in use today. For example, concentrations reduce from 20-80 ppbv for $\mathrm{NO}_{2}$ and 55 000-215000 $\mathrm{cc}^{-1}$ for PNC to less than $12 \mathrm{ppbv}$ and $30000 \mathrm{cc}^{-1}$, respectively, between a highway and a residential area over a distance of 
less than $1 \mathrm{~km}$ in the residential area of Anjou. While such gradients are being predicted for a limited number of pollutants by dispersion or LUR models or other hybrid models, as discussed in the Introduction, stationary monitoring networks clearly cannot account for them. Although multipollutant mobile studies such as those described in this paper can help provide the information needed, they are not feasible in many locations (mainly due to the high costs involved). The relatively recent emergence of portable technologies for measurements of environmental parameters (i.e., coupling portable digital devices and GPS with microsensors for air pollution (Mead et al., 2013) atmospheric parameters and biomonitoring in distributed stationary or mobile sensors networks) may help fill the gap in our ability to estimate the spatiotemporal variability at the intra-urban scale, though likely with some cost to measurement accuracy or precision and only for certain pollutants.

\section{Summary and conclusions}

Although mobile measurement campaigns have often been used to characterize intra-urban variability in air pollution, most have been based upon short periods and it is not known whether the patterns observed reflect typical or long-term conditions. When applied for evaluating average or longterm spatial patterns a mobile lab has two main limitations: its inherent inability to take simultaneous measurements at multiple locations and the limited number of measurement days that can be done at multiple locations due to cost. This study evaluated and applied a mobile monitoring approach that was designed to reduce the effects of these limitations in order to infer intra-urban variability of multiple pollutants representative of long-term exposure patterns.

The approach we evaluated was based on repeated measurements along the same route covering a wide variety of urban micro-environments on multiple days, different seasons and different times of the day. This approach has the advantage of covering a relatively large spatial domain that surpasses what an AQ monitoring network can achieve, even monitoring enhanced by additional satellite sites. Comparison of the average concentrations derived from the mobile lab at permanent monitoring sites showed that when a site was visited 18 or more times the actual annual averages could be estimated to within $25 \%$ for $\mathrm{NO}_{2}, \mathrm{NO}_{\mathrm{x}}, \mathrm{CO}$ and $\mathrm{O}_{3}$ and within $30 \%$ for $\mathrm{PM}_{2.5}$. Maximum representativeness errors were almost $60 \%$ for $\mathrm{SO}_{2}$ and over $100 \%$ for $\mathrm{NO}$. As expected, errors tended to be greater when fewer visits were completed. The mobile survey also correctly identified the larger spatial differences seen between some of the AQ monitoring network sites. Furthermore, comparison of mobile lab average concentrations across the full driving route in east Montreal showed that concentration variations observed among locations were considerably greater than the representativeness errors. This suggests that the deployment approach undertaken with CRUISER was sufficient to detect true spatial differences in average concentrations. Therefore, we conclude that it is feasible for a mobile lab survey to provide a large amount of spatial data in order to inform on chronic exposure assessment. Such data can then be applyed for a understanding of the distribution of population risk and for developing exposure models. Ideally, more long-term sites measuring a greater number of pollutants and across contrasting locations are needed in future studies in order to be able to carry out a more detailed evaluation and optimization of mobile deployment strategies designed to characterize longterm patterns.

Mobile labs, such as CRUISER, have a greater capability to characterize spatial patterns for multiple pollutants compared to intensive fixed-site monitoring. The results shown in this paper, based upon best estimates of longer-term averages, have uniquely quantified the magnitude of exposure differences for more pollutants simultaneously than has previously been studied. In Levy et al. (2014) these differences were assessed in terms of multipollutant spatial correlations. In this paper, these differences were assessed in the context of evaluating the representativeness of routine monitoring locations in Montreal and in the context of impacts from a complex mixture of emission sources. This included mobile sources, marine sources, heavy and light industry, small businesses and residential heating, including wood smoke. Longterm average concentrations were also examined in terms of the impact of a busy highway deep into an adjacent residential area, also comparing gradients among pollutants. The CRUISER deployment also involved a large coverage of east Montreal to provide observations representative of longerterm conditions over a diverse range of urban microenvironments.

Through examination of both maps depicting the overall variability for several different pollutants and of smallscale covariations in pollutants, we identified how the impact of sources varies spatially. For example, while it was well known that $\mathrm{SO}_{2}$ is emitted from the petrochemical facilities, with concurrent measurement of benzene and $\mathrm{NO}_{2}$, we were able to show that in some parts of east Montreal $\mathrm{SO}_{2}$ was associated with a different source, more likely marine vessels. Closer to the petrochemical facilities we showed how the heterogeneous nature of such facilities leads to small-scale (i.e., $\sim 100 \mathrm{~m}$ ) differences in the mix of pollutants affecting the surrounding area. Thus, systematic mobile measurement of multiple pollutants can be a valuable approach for gaining more insight into which sources have a greater long-term impact on local air quality and how these impacts vary on relatively small spatial scales.

Through examples comparing a range of locations to each other and to the nearest monitoring site, we quantitatively demonstrated to what extent exposure can be influenced by spending time in different common microenvironments, such as commercial areas and intersections of busier roadways. The mobile survey demonstrated that the routine monitoring 
sites are providing representative information on neighborhood background conditions throughout the portion(s) of east Montreal they are expected to represent. However, relatively short distances away (i.e., $100 \mathrm{~m}$ ) from locations experiencing background conditions, in areas where residents can be expected to spend time, concentrations for some pollutants (e.g., $\mathrm{NO}_{2}$, PNC) can be a factor of 2 higher. The extent of this small-scale variability depends upon source. The distribution of traffic leads to the greatest local-scale variability, while the impact of industrial facilities tends to vary on larger scales (i.e., $500 \mathrm{~m}$ ). However, as described above, the nature of this impact can vary on smaller scales in the case of large facilities involving a range of processes.

While a large amount of data are available on traffic air pollution gradients downwind of roadways, the CRUISER measurements are unique due to the relatively large number of different days and times the measurements represent, the simultaneous measurement of 23 separate parameters and the greater distance away that was explored. From these data we showed that the rate of decay in concentration with distance differs by pollutant. This is related to differing atmospheric processes occurring on short timescales. Moreover, we reported some evidence suggesting that while concentrations of some of the pollutants decay to background levels within a relatively short distance $(<50 \mathrm{~m})$ from a highway, some $\left(\mathrm{NO}_{2}, \mathrm{CO}\right.$ and traffic-related organic particles (HOA)) remain elevated up to $700 \mathrm{~m}$. Clearly, the mixture of traffic-related air pollution is complex and variable on multiple scales and not all the details were explored in this paper. However, of importance here is that some aspects of this mixture, and likely unmeasured components, may be felt above urban background levels on a long-term, chronic basis significantly beyond $500 \mathrm{~m}$.

In order to improve understanding of the overall impact of chronic air pollutant exposures in urban areas, future studies examining intra-urban variability of air pollutants will need better exposure predictions than currently available. One possible path to follow is to combine several modeling approaches (e.g., dispersion, air quality and LUR models) as well as different measurement techniques (e.g., remote sensing and mobile measurements). Furthermore, with improvement in publicly available databases on small-scale emitters, emerging technologies (e.g., distributed sensors networks) and statistical modeling approaches, some progress with these challenges can be expected, although understanding combined and differential multipollutant effects will remain a significant challenge.

The Supplement related to this article is available online at doi:10.5194/acp-14-7173-2014-supplement.
Acknowledgements. Financial support for this research was from the federal government of Canada's Clean Air Regulatory Agenda and the PERD Particles and Related Emissions Program, Project 12.007. Ilan Levy gratefully acknowledges support by a post-doctoral fellowship from the Environment and Health Fund, Jerusalem, Israel, and Natural Sciences and Engineering Research of Canada Visiting Fellowship in Canadian Government Laboratories. The authors also acknowledge the Montréal Station d'épuration des eaux useée, and Jean-R.-Marcotte (Paul André Leduc) for providing a safe location for CRUISER to park and obtain electrical power throughout the study. The Ville de Montreal is acknowledged for provision of the $1 \mathrm{~min}$ monitoring site data and Andre Germain, Montreal Sante Publique and Health Canada for providing helpful insight in study planning.

Edited by: W. Birmili

\section{References}

Adar, S. D., Sheppard, L., Vedal, S., Polak, J. F., Sampson, P. D., Roux, A. V. D., Budoff, M., Jacobs Jr, D. R., Barr, R. G., and Watson, K.: Fine particulate air pollution and the progression of carotid intima-medial thickness: a prospective cohort study from the multi-ethnic study of atherosclerosis and air pollution, PLoS Medicine, 10, e1001430, 2013.

Beckerman, B., Jerrett, M., Brook, J. R., Verma, D. K., Arain, M. A., and Finkelstein, M. M.: Correlation of nitrogen dioxide with other traffic pollutants near a major expressway, Atmos. Environ., 42, 275-290, doi:10.1016/j.atmosenv.2007.09.042, 2008.

Beckerman, B. S., Jerrett, M., Martin, R. V., van Donkelaar, A., Ross, Z., and Burnett, R. T.: Application of the deletion/substitution/addition algorithm to selecting land use regression models for interpolating air pollution measurements in California, Atmos. Environ., 77, 172-177, doi:10.1016/j.atmosenv.2013.04.024, 2013.

Beevers, S. D., Kitwiroon, N., Williams, M. L., and Carslaw, D. C.: One way coupling of CMAQ and a road source dispersion model for fine scale air pollution predictions, Atmos. Environ., 59, 4758, 2012.

Bergeron, O. and Strachan, I. B.: Wintertime radiation and energy budget along an urbanization gradient in Montreal, Canada, Int. J. Climatol., 32, 137-152, doi:10.1002/joc.2246, 2012.

Brauer, M., Hoek, G., Smit, H. A., de Jongste, J. C., Gerritsen, J., Postma, D. S., Kerkhof, M., and Brunekreef, B.: Air pollution and development of asthma, allergy and infections in a birth cohort, Eur. Respir. J., 29, 879-888, 2007.

Brauer, M., Hoek, G., Vliet, P. van, Meliefste, K., Fischer, P., Gehring, U., Heinrich, J., Cyrys, J., Bellander, T., Lewne, M., and Brunekreef, B.: Estimating Long-Term Average Particulate Air Pollution Concentrations: Application of Traffic Indicators and Geographic Information Systems, Epidemiology, 14, 228239, 2003.

Brauer, M., Lencar, C., Tamburic, L., Koehoorn, M., Demers, P., and Karr, C.: A Cohort Study of Traffic-Related Air Pollution Impacts on Birth Outcomes, Environ. Health Perspect., 116, 680686, doi:10.1289/ehp.10952, 2008.

Brook, J. R., Burnett, R. T., Dann, T. F., Cakmak, S., Goldberg, M. S., Fan, X. and Wheeler, A. J.: Further interpretation of the 
acute effect of nitrogen dioxide observed in Canadian time-series studies, J. Expos. Sci. Environ. Epidemiol., 17, S36-S44, 2007.

Brook, J. R., Levy, I., and Mihele, C.: From near-road to urban background: lessons learned from mobile lab monitoring, EM Magazine, 2013.

Brook, R. D., Jerrett, M., Brook, J. R., Bard, R. L., and Finkelstein, M. M.: The Relationship Between Diabetes Mellitus and TrafficRelated Air Pollution, Journal of Occupational and Environmental Medicine, 50, 32-38, doi:10.1097/JOM.0b013e31815dba70, 2008.

Brook, R. D., Rajagopalan, S., Pope, C. A., 3rd, Brook, J. R., Bhatnagar, A., Diez-Roux, A. V., Holguin, F., Hong, Y., Luepker, R. V., Mittleman, M. A., Peters, A., Siscovick, D., Smith, S. C., Whitsel, L., Kaufman, J. D. and on behalf of the American Heart Association Council on Epidemiology and Prevention, C. on the K. in C. D.: Particulate Matter Air Pollution and Cardiovascular Disease, Circulation, 121, 2331-2378, doi:10.1161/CIR.0b013e3181dbece1, 2010.

Bukowiecki, N., Dommen, J., Prévôt, A. S. H., Weingartner, E., and Baltensperger, U.: Fine and ultrafine particles in the Zürich (Switzerland) area measured with a mobile laboratory: an assessment of the seasonal and regional variation throughout a year, Atmos. Chem. Phys., 3, 1477-1494, doi:10.5194/acp-3-1477-2003, 2003.

Busque, D., Paradis, J., and Proulx, M.: Fine Particles and Ozone in Québec Relative to the Canada-wide Standards (2009 Report), Ministère du Développement durable, de l'Environnement et des Parcs, Direction des politiques de la qualité de l'atmosphère, Québec, 2009.

Canagaratna, M. R., Onasch, T. B., Wood, E. C., Herndon, S. C., Jayne, J. T., Cross, E. S., Miake-Lye, R. C., Kolb, C. E., and Worsnop, D. R.: Evolution of vehicle exhaust particles in the atmosphere, J. Air Waste Manage. Assoc., 60, 1192-1203, 2010.

Costabile, F., Birmili, W., Klose, S., Tuch, T., Wehner, B., Wiedensohler, A., Franck, U., König, K., and Sonntag, A.: Spatiotemporal variability and principal components of the particle number size distribution in an urban atmosphere, Atmos. Chem. Phys., 9, 3163-3195, doi:10.5194/acp-9-3163-2009, 2009.

Crooks, J. and Isakov, V.: A wavelet-based approach to blending observations with deterministic computer models to resolve the intraurban air pollution field, J. Air Waste Manage. Assoc., 63, 1369-1385, 2013.

Crouse, D. L., Goldberg, M. S., and Ross, N. A.: A prediction-based approach to modelling temporal and spatial variability of trafficrelated air pollution in Montreal, Canada, Atmos. Environ., 43, 5075-5084, doi:10.1016/j.atmosenv.2009.06.040, 2009.

Crouse, D. L., Goldberg, M. S., Ross, N. A., Chen, H., and Labrèche, F.: Postmenopausal Breast Cancer Is Associated with Exposure to Traffic-Related Air Pollution in Montreal, Canada: A Case-Control Study, Environ. Health Perspect., 118, 1578$1583,2010$.

Cyrys, J., Hochadel, M., Gehring, U., Hoek, G., Diegmann, V., Brunekreef, B., and Heinrich, J.: GIS-Based Estimation of Exposure to Particulate Matter and $\mathrm{NO}_{2}$ in an Urban Area: Stochastic versus Dispersion Modeling, Environ. Health Perspect., 113, 987-992, doi:10.1289/ehp.7662, 2005.

Cyrys, J., Pitz, M., Arx, M. E. H., Künzli, N., and Heinrich, J.: Evaluation of A Sampling Strategy for Estimation of Long-term
Pm2.5 Exposure for Epidemiological Studies, Environ. Monit Assess., 119, 161-171, doi:10.1007/s10661-005-9020-9, 2006.

Daum, P. H., Kleinman, L. I., Springston, S. R., Nunnermacker, L. J., Lee, Y.-N., Weinstein-Lloyd, J., Zheng, J., and Berkowitz, C. M.: A comparative study of $\mathrm{O} 3$ formation in the Houston urban and industrial plumes during the 2000 Texas Air Quality Study, J. Geophys. Res., 108, 18 pp., doi:200310.1029/2003JD003552, 2003.

Dijkema, M. B., Gehring, U., van Strien, R. T., van der Zee, S. C., Fischer, P., Hoek, G., and Brunekreef, B.: A Comparison of Different Approaches to Estimate Small-Scale Spatial Variation in Outdoor NO2 Concentrations, Environ. Health Perspect., 119, 670-675, doi:10.1289/ehp.0901818, 2011.

Dionisio, K. L., Rooney, M. S., Arku, R. E., Friedman, A. B., Hughes, A. F., Vallarino, J., Agyei-Mensah, S., Spengler, J. D., and Ezzati, M.: Within-Neighborhood Patterns and Sources of Particle Pollution: Mobile Monitoring and Geographic Information System Analysis in Four Communities in Accra, Ghana, Environ. Health Perspect., 118, 607-613, doi:10.1289/ehp.0901365, 2010.

Dobbin, N. A., Wheeler, A. J., Smargiassi, A., Bartlett, S., Liu, L., Shutt, R., Kauri, L. M., Mallach, G., Valois, M.-F., and Goldberg, M. S.: Lung Inflammation among Children with Asthma Exposed to Industrial and Traffic Pollution, Environ. Health Perspect., Barcelona, Spain., 2011.

Durant, J. L., Ash, C. A., Wood, E. C., Herndon, S. C., Jayne, J. T., Knighton, W. B., Canagaratna, M. R., Trull, J. B., Brugge, D., Zamore, W., and Kolb, C. E.: Short-term variation in nearhighway air pollutant gradients on a winter morning, Atmos. Chem. Phys., 10, 8341-8352, doi:10.5194/acp-10-8341-2010, 2010.

Eeftens, M., Beelen, R., de Hoogh, K., Bellander, T., Cesaroni, G., Cirach, M., Declercq, C., Dėdelè, A., Dons, E., de Nazelle, A., Dimakopoulou, K., Eriksen, K., Falq, G., Fischer, P., Galassi, C., Gražulevičienè, R., Heinrich, J., Hoffmann, B., Jerrett, M., Keidel, D., Korek, M., Lanki, T., Lindley, S., Madsen, C., Mölter, A., Nádor, G., Nieuwenhuijsen, M., Nonnemacher, M., Pedeli, X., Raaschou-Nielsen, O., Patelarou, E., Quass, U., Ranzi, A., Schindler, C., Stempfelet, M., Stephanou, E., Sugiri, D., Tsai, M.-Y., Yli-Tuomi, T., Varró, M. J., Vienneau, D., Klot, S. von, Wolf, K., Brunekreef, B. and Hoek, G.: Development of Land Use Regression Models for PM2.5, PM2.5 Absorbance, PM10 and PMcoarse in 20 European Study Areas; Results of the ESCAPE Project, Environ. Sci. Technol., 46, 11195-11205, doi:10.1021/es301948k, 2012.

Environment Canada: National Pollutant Release Inventory, Tracking Pollution in Canada, available from: http://www.ec.gc.ca/ inrp-npri/default.asp (last access: 27 September 2010), 2006.

Freiman, M. T., Hirshel, N., and Broday, D. M.: Urban-scale variability of ambient particulate matter attributes, Atmos. Environ., 40, 5670-5684, doi:10.1016/j.atmosenv.2006.04.060, 2006.

Fujita, E. M., Campbell, D. E., Patrick Arnott, W., Lau, V., and Martien, P. T.: Spatial variations of particulate matter and air toxics in communities adjacent to the Port of Oakland, J. Air Waste Manage. Assoc., 63, 1399-1411, 2013.

Fujita, E. M., Campbell, D. E., Zielinska, B., Arnott, W. P. and Chow, J. C.: Concentrations of air toxics in motor vehicledominated environments, Res. Rep. Health Eff. Inst., 156, 3-77, 2011. 
Gehring, U., Wijga, A. H., Brauer, M., Fischer, P., de Jongste, J. C., Kerkhof, M., Oldenwening, M., Smit, H. A., and Brunekreef, B.: Traffic-related Air Pollution and the Development of Asthma and Allergies during the First 8 Years of Life, Am. J. Respir. Crit. Care Med., 181, 596-603, doi:10.1164/rccm.200906-08580C, 2010

Gertler, A., Kuhns, H., Abu-Allaban, M., Damm, C., Gillies, J., Etyemezian, V., Clayton, R., and Proffitt, D.: A case study of the impact of Winter road sand/salt and street sweeping on road dust re-entrainment, Atmos. Environ., 40, 5976-5985, doi:10.1016/j.atmosenv.2005.12.047, 2006.

Gilbert, N. L., Goldberg, M. S., Beckerman, B., Brook, J. R., and Jerrett, M.: Assessing spatial variability of ambient nitrogen dioxide in Montréal, Canada, with a land-use regression model, J Air Waste Manag Assoc, 55, 1059-1063, 2005.

Gryparis, A., Coull, B. A., and Schwartz, J.: Controlling for confounding in the presence of measurement error in hierarchical models: a Bayesian approach, J. Expos. Sci. Environ. Epidemiol., 17, S20-S28, doi:10.1038/sj.jes.7500624, 2007.

Hagler, G. S. W., Thoma, E. D., and Baldauf, R. W.: High-resolution mobile monitoring of carbon monoxide and ultrafine particle concentrations in a near-road environment, J. Air Waste Manag. Assoc., 60, 328-336, 2010.

Henderson, S. B., Beckerman, B., Jerrett, M., and Brauer, M.: Application of Land Use Regression to Estimate Long-Term Concentrations of Traffic-Related Nitrogen Oxides and Fine Particulate Matter, Environ. Sci. Technol., 41, 2422-2428, doi:10.1021/es0606780, 2007.

Hirtl, M. and Baumann-Stanzer, K.: Evaluation of two dispersion models (ADMS-Roads and LASAT) applied to street canyons in Stockholm, London and Berlin, Atmos. Environ., 41, 59595971, doi:10.1016/j.atmosenv.2007.03.026, 2007.

Hochadel, M., Heinrich, J., Gehring, U., Morgenstern, V., Kuhlbusch, T., Link, E., Wichmann, H.-E. and Krämer, U.: Predicting long-term average concentrations of traffic-related air pollutants using GIS-based information, Atmos. Environ., 40, 542-553, doi:10.1016/j.atmosenv.2005.09.067, 2006.

Hu, S., Fruin, S., Kozawa, K., Mara, S., Paulson, S. E. and Winer, A. M.: A wide area of air pollutant impact downwind of a freeway during pre-sunrise hours, Atmos. Environ., 43, 2541-2549, doi:10.1016/j.atmosenv.2009.02.033, 2009.

Hystad, P., Setton, E., Cervantes, A., Poplawski, K., Deschenes, S., Brauer, M., van Donkelaar, A., Lamsal, L., Martin, R., Jerrett, M., and Demers, P.: Creating national air pollution models for population exposure assessment in Canada, Environ. Health Perspect., 119, 1123-1129, doi:10.1289/ehp.1002976, 2011.

Isakov, V., Irwin, J. S., and Ching, J.: Using CMAQ for Exposure Modeling and Characterizing the Subgrid Variability for Exposure Estimates, J. Appl. Meteorol. Climatol., 46, 1354-1371, doi:10.1175/JAM2538.1, 2007a.

Isakov, V., Touma, J. S., and Khlystov, A.: A method of assessing air toxics concentrations in urban areas using mobile platform measurements, J. Air Waste Manag. Assoc., 57, 1286-1295, $2007 \mathrm{~b}$.

Janssen, N. A. H., Hoek, G., Simic-Lawson, M., Fischer, P., van Bree, L., ten Brink, H., Keuken, M., Atkinson, R. W., Anderson, H. R., Brunekreef, B., and Cassee, F. R.: Black Carbon as an Additional Indicator of the Adverse Health Effects of Airborne Particles Compared with PM10 and PM$_{2.5}$, Environ. Health Perspect., 119, 1691-1699, doi:10.1289/ehp.1003369, 2011.
Janssen, N. A., Schwartz, J., Zanobetti, A. and Suh, H. H.: Air conditioning and source-specific particles as modifiers of the effect of $\mathrm{PM}_{10}$ on hospital admissions for heart and lung disease, Environ. Health Perspect., 110, 43-49, 2002.

Jerrett, M., Arain, M. A., Kanaroglou, P., Beckerman, B., Crouse, D. L., Gilbert, N. L., Brook, J. R., Finkelstein, N., and Finkelstein, M. M.: Modeling the intraurban variability of ambient traffic pollution in Toronto, Canada, J. Toxicol. Environ. Health, 70, 200-212, 2007.

Jerrett, M., Finkelstein, M. M., Brook, J. R., Arain, M. A., Kanaroglou, P., Stieb, D. M., Gilbert, N. L., Verma, D., Finkelstein, N., Chapman, K. R., and Sears, M. R.: A Cohort Study of Traffic-Related Air Pollution and Mortality in Toronto, Ontario, Canada, Environ. Health Perspect., 117, 772-777, doi:10.1289/ehp.11533, 2009.

Johnson, M., Isakov, V., Touma, J. S., Mukerjee, S., and Özkaynak, H.: Evaluation of land-use regression models used to predict air quality concentrations in an urban area, Atmos. Environ., 44, 3660-3668, doi:10.1016/j.atmosenv.2010.06.041, 2010.

Kanaroglou, P. S., Jerrett, M., Morrison, J., Beckerman, B., Arain, M. A., Gilbert, N. L., and Brook, J. R.: Establishing an air pollution monitoring network for intra-urban population exposure assessment: A location-allocation approach, Atmos. Environ., 39, 2399-2409, doi:10.1016/j.atmosenv.2004.06.049, 2005.

Karner, A. A., Eisinger, D. S., and Niemeier, D. A.: Near-Roadway Air Quality: Synthesizing the Findings from Real-World Data, Environ. Sci. Technol., 44, 5334-5344, doi:10.1021/es100008x, 2010.

Kelly, F. J. and Fussell, J. C.: Size, source and chemical composition as determinants of toxicity attributable to ambient particulate matter, Atmos. Environ., 60, 504-526, 2012.

Larson, T., Henderson, S. B., and Brauer, M.: Mobile monitoring of particle light absorption coefficient in an urban area as a basis for land use regression, Environ. Sci. Technol., 43, 4672-4678, 2009.

Larson, T., Su, J., Baribeau, A.-M., Buzzelli, M., Setton, E., and Brauer, M.: A Spatial Model of Urban Winter Woodsmoke Concentrations, Environ. Sci. Technol., 41, 24292436, doi:10.1021/es0614060, 2007.

Lee, C. J., Brook, J. R., Evans, G. J., Martin, R. V., and Mihele, C.: Novel application of satellite and in-situ measurements to map surface-level $\mathrm{NO}_{2}$ in the Great Lakes region, Atmos. Chem. Phys., 11, 11761-11775, doi:10.5194/acp-11-11761-2011, 2011.

Levy, I., Mihele, C., Lu, G., Narayan, J., and Brook, J. R.: Evaluating Multipollutant Exposure and Urban Air Quality: Pollutant Interrelationships, Neighborhood Variability, and Nitrogen Dioxide as a Proxy Pollutant, Environ. Health Perspect., 122, 65-72, doi:10.1289/ehp.1306518, 2014.

Levy, J. I., Houseman, E. A., Spengler, J. D., Loh, P., and Ryan, L.: Fine particulate matter and polycyclic aromatic hydrocarbon concentration patterns in Roxbury, Massachusetts: a communitybased GIS analysis, Environ. Health Perspect., 109, 341-347, 2001.

Lippmann, M., Chen, L. C., Gordon, T., Ito, K., and Thurston, G. D.: National Particle Component Toxicity (NPACT) Initiative: Integrated Epidemiologic and Toxicologic Studies of the Health Effects of Particulate Matter Components., Health Effects Institute, Boston, Mass., 2013. 
Makar, P. A., Zhang, J., Gong, W., Stroud, C., Sills, D., Hayden, K. L., Brook, J., Levy, I., Mihele, C., Moran, M. D., Tarasick, D. W., He, H., and Plummer, D.: Mass tracking for chemical analysis: the causes of ozone formation in southern Ontario during BAQS-Met 2007, Atmos. Chem. Phys., 10, 11151-11173, doi:10.5194/acp-10-11151-2010, 2010.

Marshall, J. D., Nethery, E., and Brauer, M.: Withinurban variability in ambient air pollution: Comparison of estimation methods, Atmos Environ, 42, 1359-1369, doi:10.1016/j.atmosenv.2007.08.012, 2008.

Martuzevicius, D., Grinshpun, S. A., Reponen, T., Górny, R. L., Shukla, R., Lockey, J., Hu, S., McDonald, R., Biswas, P., Kliucininkas, L., and LeMasters, G.: Spatial and temporal variations of PM2.5 concentration and composition throughout an urban area with high freeway density - the Greater Cincinnati study, Atmos. Environ., 38, 1091-1105, doi:10.1016/j.atmosenv.2003.11.015, 2004.

Mauderly, J. L. and Samet, J. M.: Is There Evidence for Synergy Among Air Pollutants in Causing Health Effects?, Environ. Health Perspect., 117, 1-6, doi:10.1289/ehp.11654, 2009.

Mead, M. I., Popoola, O. A. M., Stewart, G. B., Landshoff, P., Calleja, M., Hayes, M., Baldovi, J. J., McLeod, M. W., Hodgson, T. F., and Dicks, J.: The use of electrochemical sensors for monitoring urban air quality in low-cost, high-density networks, Atmos. Environ., 70, 186-203, 2013.

Miller, L., Xu, X., Grgicak-Mannion, A., Brook, J., and Wheeler, A.: Multi-season, multi-year concentrations and correlations amongst the BTEX group of VOCs in an urbanized industrial city, Atmos. Environ., 61, 305-315, doi:10.1016/j.atmosenv.2012.07.041, 2012.

Monn, C.: Exposure assessment of air pollutants: a review on spatial heterogeneity and indoor/outdoor/personal exposure to suspended particulate matter, nitrogen dioxide and ozone, Atmos. Environ., 35, 1-32, doi:10.1016/S1352-2310(00)00330-7, 2001.

Nordling, E., Berglind, N., Melén, E., Emenius, G., Hallberg, J., Nyberg, F., Pershagen, G., Svartengren, M., Wickman, M., and Bellander, T.: Traffic-Related Air Pollution and Childhood Respiratory Symptoms, Function and Allergies, Epidemiology, 19, 401-408, doi:10.1097/EDE.0b013e31816a1ce3, 2008.

Patton, A. P., Collins, C., Naumova, E. N., Zamore, W., Brugge, D., and Durant, J. L.: An hourly regression model for ultrafine particles in a near-highway urban area, Environ. Sci. Technol., 2014.

Pennington, M. R., Klems, J. P., Bzdek, B. R., and Johnston, M. V.: Nanoparticle chemical composition and diurnal dependence at the CalNex Los Angeles ground site, J. Geophys. Res., 117, 9 pp., doi:10.1029/2011JD017061, 2012.

Pope III, C. A. and Dockery, D. W.: Health effects of fine particulate air pollution: lines that connect, J. Air Waste Manag. Assoc., 56, 709-742, 2006.

RDCT: (R Development Core Team). R: A Language and Environment for Statistical Computing, R Foundation for Statistical Computing, Vienna, Austria. [online] Available from: http: //www.R-project.org, 2009.

Ren, C. and Tong, S.: Health effects of ambient air pollution - recent research development and contemporary methodological challenges, Environmental Health, 7, 56, doi:10.1186/1476-069X-7$56,2008$.
Rivera, M., Basagaña, X., Aguilera, I., Foraster, M., Agis, D., de Groot, E., Perez, L., Mendez, M. A., Bouso, L. and Targa, J.: Association between long-term exposure to traffic-related air pollution and subclinical atherosclerosis: the REGICOR study, Environ. Health Perspect., 121(2), 223, 2013.

Rohr, A. C. and Wyzga, R. E.: Attributing health effects to individual particulate matter constituents, Atmos. Environ., 62, 130152, 2012.

Shrestha, K. L., Kondo, A., Kaga, A., and Inoue, Y.: Highresolution modeling and evaluation of ozone air quality of Osaka using MM5-CMAQ system, J. Environ. Sci., 21, 782-789, doi:10.1016/S1001-0742(08)62341-4, 2009.

Smargiassi, A., Kosatsky, T., Hicks, J., Plante, C., Armstrong, B., Villeneuve, P. J., and Goudreau, S.: Risk of Asthmatic Episodes in Children Exposed to Sulfur Dioxide Stack Emissions from a Refinery Point Source in Montreal, Canada, Environ. Health Perspect., 117, 653-659, doi:10.1289/ehp.0800010, 2009.

Spengler, J. D., Lwebuga-Mukasa, J., Vallarino, J., Melly, S., Chillrud, S., Baker, J., and Minegishi, T.: Air toxics exposure from vehicle emissions at a U.S. border crossing: Buffalo Peace Bridge Study., Health Effects Institute, Boston, Mass., 2011.

Statistics Canada: Population of census metropolitan areas, available from: http://www40.statcan.gc.ca/101/cst01/demo05a-eng. htm, (last access: 22 June 2011), 2011.

Sun, Y. L., Zhang, Q., Schwab, J. J., Chen, W.-N., Bae, M.-S., Hung, H.-M., Lin, Y.-C., Ng, N. L., Jayne, J., Massoli, P., Williams, L. R., and Demerjian, K. L.: Characterization of near-highway submicron aerosols in New York City with a high-resolution aerosol mass spectrometer, Atmos. Chem. Phys., 12, 2215-2227, doi:10.5194/acp-12-2215-2012, 2012.

Szpiro, A. A., Sampson, P. D., Sheppard, L., Lumley, T., Adar, S. D., and Kaufman, J. D.: Predicting intra-urban variation in air pollution concentrations with complex spatio-temporal dependencies, Environmetrics, 21, 606-631, doi:10.1002/env.1014, 2010.

Thiering, E., Cyrys, J., Kratzsch, J., Meisinger, C., Hoffmann, B., Berdel, D., von Berg, A., Koletzko, S., Bauer, C., and Heinrich, J.: Long-term exposure to traffic-related air pollution and insulin resistance in children: results from the GINIplus and LISAplus birth cohorts, Diabetologia, 56, 1696-1704, 2013.

Villeneuve, P. J., Jerrett, M., Su, J., Burnett, R. T., Chen, H., Brook, J., Wheeler, A. J., Cakmak, S., and Goldberg, M. S.: A cohort study of intra-urban variations in volatile organic compounds and mortality, Toronto, Canada, Environ. Poll., doi:10.1016/j.envpol.2012.12.022, 2013.

Wang, R., Henderson, S. B., Sbihi, H., Allen, R. W. and Brauer, M.: Temporal stability of land use regression models for traffic-related air pollution, Atmos. Environ., 64, 312-319, doi:10.1016/j.atmosenv.2012.09.056, 2013.

Weimer, S., Mohr, C., Richter, R., Keller, J., Mohr, M., Prévôt, A. S. H., and Baltensperger, U.: Mobile measurements of aerosol number and volume size distributions in an Alpine valley: Influence of traffic versus wood burning, Atmos. Environ., 43, 624-630, doi:10.1016/j.atmosenv.2008.10.034, 2009.

Westerdahl, D., Fruin, S., Sax, T., Fine, P. M., and Sioutas, C.: Mobile platform measurements of ultrafine particles and associated pollutant concentrations on freeways and residential streets in Los Angeles, Atmos. Environ., 39, 3597-3610, doi:16/j.atmosenv.2005.02.034, 2005. 
Wheeler, A. J., Smith-Doiron, M., Xu, X., Gilbert, N. L., and Brook, J. R.: Intra-urban variability of air pollution in Windsor, Ontario - Measurement and modeling for human exposure assessment, Environ. Res., 106, 7-16, doi:10.1016/j.envres.2007.09.004, 2008.

Xu, X., Brook, J. R., and Guo, Y.: A statistical assessment of saturation and mobile sampling strategies to estimate long-term average concentrations across urban areas, J. Air Waste Manag. Assoc., 57, 1396-1406, 2007.
Yuval, Bekhor, S., and Broday, D. M.: Data-driven nonlinear optimisation of a simple air pollution dispersion model generating high resolution spatiotemporal exposure, Atmos. Environ., 79, 261-270, doi:10.1016/j.atmosenv.2013.06.005, 2013.

Zwack, L. M., Paciorek, C. J., Spengler, J. D., and Levy, J. I.: Modeling Spatial Patterns of Traffic-Related Air Pollutants in Complex Urban Terrain, Environ. Health Perspect., 119, 852-859, doi:10.1289/ehp.1002519, 2011. 